\title{
Classe Social e Desigualdade de Gênero no Brasil*
}

\author{
José Alcides Figueiredo Santos
}

\begin{abstract}
$\mathrm{O}$ mundo social é constituído da interação estrutural entre as categorias que o dividem. Investiga-se aqui a proposição de que a desigualdade de gênero de renda no Brasil seria influenciada pelo contexto de classe social. Estima-se a distância de gênero de rendimentos entre homens e mulheres no Brasil aplicando novas soluções metodológicas, que revelam a existência de uma elevada desigualdade de tratamento de gênero entre pessoas situadas nas mesmas circunstâncias sociais. São investigados determinados componentes relevantes dessa desigualdade econômica de gênero e, por fim, analisados os efeitos condicionantes dos contextos de classe na redução ou exacerbação da diferença de gênero de rendimentos.
\end{abstract}

\footnotetext{
* Este estudo contou com um auxílio de pesquisa principal da Fundação de Amparo à Pesquisa do Estado de Minas Gerais - Fapemig e um complementar do Conselho Nacional de Desenvolvimento Científico e Tecnológico-CNPq. Agradeço ao professor Trond Petersen, do Departamento de Sociologia da Universidade da Califórnia-Berkeley, a oportunidade de conhecer seu inovador trabalho metodológico, que fundamenta a escolha do modelo estatístico usado nesta investigação. Uma versão preliminar do estudo, usando um modelo de regressão OLS (Ordinary Least Squares), foi apresentada no grupo de trabalho Gênero na Contemporaneidade, do XXIX Encontro Anual da Associação Nacional de Pós-Graduação e Pesquisa em Ciências Sociais - Anpocs, em 2005. O autor agradece os comentários dos integrantes. O estudo contou ainda com a participação de duas bolsistas de iniciação científica, Lara Cruz Correa e Juliana de Souza Barbosa, que colaboraram no manuseio dos dados.
}

DADOS - Revista de Ciências Sociais, Rio de Janeiro, Vol. 51, n²2, 2008, pp. 353 a 402. 
Esta iniciativa se inscreve em um programa de investigação de maior amplitude a respeito da estruturação da desigualdade social na sociedade brasileira ${ }^{1}$. O estudo focaliza a discrepância de gênero de renda considerando a especificidade de seus mecanismos - à luz do contexto subjacente da estrutura da desigualdade econômica de classe. A noção sociológica de classe social foi mensurada por meio de uma classificação socioeconômica que aperfeiçoa e atualiza a tipologia utilizada em Estrutura de Posições de Classe no Brasil (Figueiredo Santos, 2002). Os fundamentos teóricos, analíticos e metodológicos das categorias empíricas dessa nova classificação foram formulados por mim em outro artigo (idem, 2005a; 2006b). Ao explorar as interações entre classe e gênero, este estudo vai além da prática comum de estimar uma diferença média de gênero de renda, o que permite refletir as dimensões diferenciadas da desigualdade de gênero.

São apresentadas, de modo sumário, as noções sociológicas de classe e de gênero que orientam este artigo - entendidas como divisões sociais geradoras de desigualdades -, assim como uma perspectiva de análise de classe da desigualdade de gênero. Situam-se determinadas abordagens econômicas e sociológicas correntes da desigualdade de gênero em recompensas econômicas. A investigação empírica é antecedida pela definição dos objetivos do estudo e pelas estratégias metodológicas escolhidas. Por fim, apresentam-se os resultados da análise dos fatores que conformam a desigualdade de gênero no Brasil e das manifestações mais relevantes do papel moderador das categorias de classe na alteração da força dos efeitos de gênero na renda pessoal.

\section{CLASSE, GÊNERO E DESIGUALDADE}

Noção de classe em vertente da tradição marxista. A noção de classe na teoria social focaliza o problema do entendimento dos sistemas de desigualdade econômica. As diferentes agendas teóricas da análise de classe organizam-se em torno de diferentes questões-chaves. O marxismo não só valoriza a perspectiva de explicação relacional das oportunidades econômicas mas também se interessa pela questão da variação histórica dos sistemas de desigualdade. O elemento distintivo da agenda marxista, no entanto, encontra-se na noção de classe social como um fundamento da opressão econômica e da exploração (Wright, 2004). $\mathrm{Na}$ abordagem de Wright, as relações de classe envolvem a distribuição desigual de direitos e poderes sobre os recursos produtivos básicos da sociedade e os resultados de seu uso. Em decorrência da natureza 
dos poderes e direitos exercidos sobre os recursos produtivos, a pessoa enfrenta uma estrutura de oportunidades, dilemas e opções nas esferas do trabalho e do consumo. Em um sistema de produção pensado em termos sociais relacionais, o que a pessoa tem condiciona o que ela deve fazer para conseguir o que obtém. As relações de classe geram um conflito social baseado nas assimetrias entre o que as pessoas têm e o que fazem com o que têm. A noção de exploração pretende oferecer um diagnóstico do processo por meio do qual as desigualdades de recompensa são geradas por desigualdades nos direitos e poderes sobre os recursos produtivos. A exploração caracteriza-se pelo fato de um grupo se beneficiar economicamente à custa de outro pela apropriação dos frutos do trabalho do grupo explorado. A apropriação do esforço de trabalho, por sua vez, requer que a atividade de trabalho seja dirigida e controlada dentro da organização social da produção. As interações de poder entre os atores sociais e os custos de extração do esforço de trabalho põem em cena a operação de mecanismos de coerção e de consenso dentro da produção. Como o explorador depende da atividade de trabalho do explorado, este retém um tipo de poder social, enraizado nas interdependências da exploração, que pode ser usado na luta por seus interesses. $\mathrm{O}$ conceito de classe centrado na noção de exploração insere-se em uma agenda teórica que vincula questões acerca dos interesses materiais das pessoas, das bases do conflito social e das possibilidades de mudança histórica (idem, 1997; 2004; 2005).

Noção de gênero: unidade e diversidade. A instituição do parentesco desempenha um papel crítico na origem da situação peculiar feminina ao representar o lugar social sancionado de encontro entre os sexos, mas o gênero enquanto princípio de classificação opera em outras instâncias do mundo social (Heilborn e Sorj, 1999). Gênero é um sistema de práticas sociais existentes dentro da sociedade, que define e constitui as pessoas como diferentes, de modo socialmente significativo, e organiza relações de desigualdade baseadas em tais diferenças (Ridgeway e Smith-Lovin, 1999). Opera em pessoas, interações sociais e instituições. Processos de institucionalização e legitimação reproduzem as desigualdades de gênero (Wharton, 2004). A noção de gênero como uma divisão social realça a idéia de que as diferenças de gênero são predominantemente de origem social e estrutural, de modo que o homem, como uma categoria, possui mais poder social do que a mulher, também como uma categoria. A identidade de gênero estrutura a experiência, o sentido dado ao mundo e as expectativas dos outros. As relações de gênero, no entanto, ao representarem desigualdades inscritas nas 
estruturas da sociedade, existem igualmente fora dos modos pelos quais as pessoas categorizam homem e mulher. Gênero é uma construção social usada para definir, explicar e justificar desigualdades (Abbott, 2000). Abordagem de gênero como uma instituição social ajuda a realçar o caráter social, a dinâmica, as complexas interseções e as múltiplas facetas das práticas de gênero (Martin, 2004).

Preocupações emergentes na literatura recente alertam para a importância de se dar "maior atenção aos níveis crescentes e elevados de desigualdade entre as mulheres, por classe e raça, ao lado da ênfase atual na desigualdade de gênero pelas feministas" (McCall, 2001:58). Convém considerar os elementos de unidade e diversidade subjacentes à noção de gênero como categoria sociológica. A sociologia deve desenvolver um entendimento mais adequado de como as mulheres, diferentes em termos de circunstâncias e experiências - por exemplo, de classe, raça e idade -, estão situadas dentro das dinâmicas da desigualdade de gênero. Essa exploração da diferença e da diversidade, contudo, não deve ser feita em prejuízo da unidade (Bradley, 1996:101-102).

A desigualdade de gênero no trabalho e na renda manifesta-se em praticamente todos os países do mundo. As disparidades de renda entre o homem e a mulher, ou a distância (gap) de renda de gênero, têm despertado um grande esforço de investigação e interpretação tanto na literatura econômica quanto na sociológica.

A desigualdade de gênero de renda na literatura econômica. A teoria econômica neoclássica considera que cada pessoa recebe como recompensa o valor da contribuição marginal do insumo (trabalho, capital ou terra) que agrega à função de produção. Baseada no modelo neoclássico, a teoria do capital humano postula que o trabalho seria recompensado pelos investimentos que as pessoas realizam em sua própria educação, treinamento e cuidados de saúde; ou seja, em seu "capital humano", que incrementa sua produtividade ou capacidade de contribuição para o produto. Essa abordagem econômica convencional privilegia as explicações pelo lado da oferta. Homens e mulheres ingressariam no mercado de trabalho com diferentes características produtivas e inclinações. Nessa ótica, parte importante da diferença de gênero de renda existente no mercado de trabalho decorreria de diferenças nas características produtivas e nas estruturas de preferência de homens e mulheres em função de escolhas voluntárias ou de condicionamentos anteriores ao ingresso no mercado, que explicariam as diferenças no montan- 
te, no tipo e no grau de depreciação do capital humano de ambos (Blau, Ferber e Winkler, 1998:141-184; Jacobsen, 1997:258-276).

A ocorrência de discriminação no mercado de trabalho desafia a ortodoxia neoclássica ao introduzir um componente "irracional" de tratamento desigual de trabalhadores igualmente produtivos, que contrasta com o princípio de maximização do lucro. Duas teorias merecem destaque especial pelo modo com que "ajustam" o princípio da racionalidade econômica com o fenômeno empírico da discriminação. Embora compatíveis com os pressupostos neoclássicos, ambas podem ser pensadas também em uma lógica explicativa diferente. A teoria da discriminação estatística considera que o empregador usaria os atributos de sexo e raça, como uma espécie de informação substitutiva, na ausência de informação adequada para avaliar o potencial de produtividade do trabalhador a um custo razoavelmente baixo, gerando uma discriminação estatística contra os indivíduos pertencentes a grupos que teriam, em média, características menos desejáveis. Já o enfoque de amontoamento considera que a concentração de certos grupos, como as mulheres, em determinados tipos de emprego, gera como conseqüência uma oferta excedente em relação à demanda por esses serviços. Isso deprime a taxa de salário dessas ocupações, quaisquer que sejam as razões que tenham levado ao amontoamento (Rima, 1996:260-271; Blau, Ferber e Winkler, 1998:207-211).

A tradição crítica da economia política analisa o tratamento adverso dado à mulher como uma conseqüência das regras explícitas e implícitas que regulam a sociedade. A discriminação não é vista como um comportamento apenas "irracional", estranho à lógica do mercado, pois cabe considerar a existência de incentivos econômicos para discriminar. Ela pode servir como um mecanismo de enfraquecimento da solidariedade e do poder de barganha dos trabalhadores, podendo ter implicações para os salários e para a segurança de emprego da parcela dos trabalhadores que indiretamente se beneficiam dela. Além disso, pode refletir um processo de adaptação organizacional que se manifesta na tendência das firmas em adotar as convenções sociais prevalecentes na sociedade. A discriminação deve ser vista como um fenômeno dinâmico, influenciado pelos ciclos da economia e pela competição entre as firmas, estabelecendo para as empresas a questão dos custos e riscos econômicos associados a mudanças para sua redução (Albelda, Drago e Shulman, 2001:178-195). 
A desigualdade de gênero de renda na literatura sociológica. A sociologia desenvolve um modo próprio de entender o papel da discriminação na explicação da distância de gênero na renda. Tem sido longamente observado, no estudo da desigualdade social, que as ideologias de diferença, como a visão essencialista de gênero, são freqüentemente convertidas em ideologias de hierarquia, como a consagração do valor cultural da primazia do homem (Charles, 2003:271). Uma noção sociológica ampla de discriminação abarca as desvantagens geradas tanto pelo tratamento diferenciado, baseado em uma categorização social atribuída às pessoas, quanto pelo impacto diferenciado do tratamento, baseado em outros fatores - associados à categoria em questão - que são insuficientemente justificados (Blank, Dabady e Citro, 2004:39-40). Existe o processo de discriminação alocativa, que faz com que a mulher seja diferencialmente alocada em posições que oferecem menores recompensas. Cabe falar também em uma discriminação valorativa enfatizada pelos estudos de valor comparável, que demonstram como as mulheres recebem menores recompensas apesar de estarem em situações de emprego comparáveis e possuírem requisitos de qualificação e outras características semelhantes aos dos homens. As formas de discriminação alocativa e valorativa implicam a segregação de homens e mulheres em diferentes ocupações. Por fim, pode-se falar em uma discriminação interna ao emprego, ou à posição, em que as mulheres recebem recompensas desiguais apesar de ocuparem a mesma posição (emprego), situada exatamente no mesmo contexto (empresa) (Petersen e Morgan, 1995:329-330).

Uma parte importante da literatura sociológica situa a segregação posicional como o fator específico mais importante na explicação da diferença de gênero de renda. $O$ tratamento desigual se processa de forma mais eficaz e "justificável" quando os diferentes grupos são separados em diferentes lugares e em papéis desigualmente recompensados (Reskin e Padavic, 1994:46 e 118). As divisões de gênero geram conseqüências no emprego e na renda por meio de determinados tipos de mecanismo social e cultural, tais como a aquisição de diferentes tipos de qualificação e credencial, papel familiar, aspiração de trabalho e familiar, discriminação e rede social (Marini e Fan, 2001:745-747). Diversos estudos usam um índice de segregação como medida sumária do fenômeno da segregação posicional. O índice de Duncan, por exemplo, mede a proporção do grupo segregado que teria de mudar de uma ocupação segregada para ambos os grupos serem distribuídos de modo mais integrado. Essa abordagem convencional unidimensional, no en- 
tanto, tem sido solapada por evidências empíricas que registram índices estáveis e/ou elevados de segregação em países que viveram modificações relevantes no status da mulher, como os países escandinavos e os Estados Unidos, e índices comparativamente baixos de segregação em países em que os papéis de gênero tradicionais são ainda fortes, como Itália, Portugal e Espanha.

Defende-se como abordagem alternativa a distinção analítica entre as formas horizontais e verticais de desigualdade distributiva a fim de captar melhor os vários componentes da segregação e suas respostas diferenciadas às tendências econômicas e sociais (Charles, 2003:268). Uma abordagem exclusivamente focada nas tendências de comportamento do nível de segregação não permite apreciar devidamente as diferentes caracterizações da desigualdade de gênero e seu papel na explicação das trajetórias da segregação. Novas contribuições apontam para a importância de atentar para o padrão de distribuição de gênero em termos dos contornos ocupacionais específicos da segregação de gênero a fim de examinar se e como as trajetórias de segregação variam através das ocupações (Weeden, 2004).

Emergem, particularmente na literatura mais recente, questionamentos acerca da representatividade das medidas sumárias da desigualdade de gênero, tais como o índice de segregação ocupacional de gênero e a diferença média de gênero de renda, por não refletirem as dimensões diferenciadas e mesmo conflitantes da desigualdade na atualidade (Charles e Grusky, 2004; McCall, 2001:25-26). McCall enfatiza que a abordagem tradicional se revela incapaz de tratar, por exemplo, as formas de desigualdade crescentes no mercado de trabalho feminino nos Estados Unidos. Como alternativa, elabora a noção de configurações de desigualdade e defende uma mudança de atenção para "a relação mutável e contingente entre estruturas de oportunidades múltiplas e concorrentes em economias regionais" (2001:21). Essa linha de investigação valoriza a articulação das perspectivas de classe, gênero e raça, de modo que "cada simples dimensão da desigualdade seja informada pelo contexto maior da desigualdade e as condições econômicas a ele subjacentes" (ibidem:192). A análise da diferença de renda, por gênero ou raça, não deve perder de vista o contexto geral da distribuição de renda, ou seja, os níveis de renda e o grau de concentração da distribuição de renda, assim como as tendências gerais de seu aumento, estabilidade ou declínio (Morris e Western, 1999). Estudos recentes indicam a importância de considerar a estrutura geral da desigualdade para en- 
tender a desigualdade de gênero. A amplitude das escalas de renda, ou seja, da distância entre os graus (rungs) da distribuição de renda, assim como a posição em que fica o trabalhador feminino mediano, afetaria fortemente o padrão prevalecente da desigualdade de gênero na renda (Gornick, 1999:231).

A desigualdade de gênero em recompensas econômicas no Brasil. No Brasil, a situação da mulher no mundo do trabalho revela-se marcada por elementos de continuidade e mudanças. Os fatores de continuidade expressam-se na concentração das mulheres em empregos de menor remuneração no setor de serviços e particularmente no segmento informal e mais desprotegido do mercado de trabalho. De outro lado, como expressão de mudanças, aumentou a participação de mulheres em ocupações não-manuais de melhor remuneração, em cargos de comando, profissões de prestígio e mesmo como proprietárias de negócios no comércio e em serviços. As discrepâncias de gênero de rendimentos persistem, apesar do progresso ocupacional, sendo que as diferenças de ganhos não podem ser atribuídas a diferenças em termos de números de horas trabalhadas e escolaridade, devendo ser creditadas aos processos de discriminação (Bruschini, 2000). Estudo dos efeitos da composição por gênero das ocupações sobre os salários mostra que persiste no Brasil uma penalidade salarial para aqueles que estão inseridos em ocupações tipicamente femininas, sendo que essa penalidade se mostra mais forte para as mulheres do que para os homens. A análise temporal do período que vai de 1981 a 1999 revelou uma tendência de aumento do hiato salarial de gênero (Oliveira, 2003:135-136).

Análise de classe da opressão e da desigualdade de gênero. A opressão de gênero define-se como uma situação em que homens e mulheres, enquanto categorias distintas de atores, diferem sistematicamente em termos de poder social e bem-estar material. As relações de gênero geram uma opressão da mulher na medida em que ela, enquanto categoria, sofre diferentes tipos de prejuízo em virtude dos padrões sociais prevalecentes nas relações entre homens e mulheres. Gênero não representa um fenômeno apenas interpessoal, pois arranjos macrossociais, tais como as leis do Estado, a estrutura do mercado de trabalho e a divisão do trabalho, afetam as práticas de gênero e são moldados por essas mesmas relações de gênero. Entretanto, não existem contradições distintivamente de gênero na esfera macro, como ocorre no caso de classe social, de modo que as intervenções emancipadoras de gênero não pre- 
cisam enfrentar os complexos problemas de coordenação no âmbito sistêmico para garantir a reprodução da sociedade como uma totalidade articulada (Wright, 1994:211-233).

Estudos comparativos internacionais conduzidos por Wright exploraram a tese geral do reforço mútuo entre as formas de desigualdade de classe e aquelas baseadas em fatores atribuídos como raça e gênero. $\mathrm{Na}$ hipótese de que as demais formas de desigualdade se traduzem em desigualdade de classe, a mulher e os grupos racialmente oprimidos devem estar sobre-representados na classe trabalhadora e sub-representados nas localizações de classe privilegiadas. Obteve-se a confirmação empírica de que a mulher, na força de trabalho, é mais proletarizada; há uma significativa desigualdade de gênero em autoridade no local de trabalho; negros são significativamente mais proletarizados; a mulher negra é o grupo mais proletarizado. Na hipótese de que a desigualdade de classe se traduz em outras formas de desigualdade, ao serem comparados países situados em determinado nível de desenvolvimento capitalista semelhante, quanto mais desiguais as relações de classe dentro do capitalismo, mais desiguais as demais formas de divisão social.

Entretanto, os estudos do autor revelaram certas surpresas empíricas sobre a questão de gênero nos seguintes aspectos: a diferença de gênero em autoridade no local de trabalho é menor nos Estados Unidos, onde existe maior desigualdade de classe, em comparação com os países social-democratas Suécia e Noruega, onde a desigualdade é menor; maridos fazem pouco trabalho doméstico independentemente da composição de classe do domicílio. Esses resultados levaram Wright (1997) a propor como reconstrução teórica a formulação de que as opressões de classe e gênero podem variar bem independentemente uma da outra. Isso significa que as lutas contra a desigualdade de gênero podem ter uma amplitude dentro do capitalismo maior do que o marxismo usualmente admitia. Na visão de Wright, os avanços na análise de classe de gênero e na análise de gênero de classe dependem de pesquisas que contribuam para clarificar, em relação a objetos de explicação (explananda) específicos, as formas de interação entre classe e gênero como processos causais. A importância causal relativa de classe e gênero depende do objeto de explicação específico em foco (idem, 2001:29-30 e 38). 


\section{HIPÓTESES, MÉTODOS E BASE DE DADOS}

Em um contexto de elevada desigualdade de renda, como o prevalecente no Brasil, não seria adequado focalizar apenas as desvantagens de oportunidades associadas aos atributos de gênero, sem considerar a estrutura da desigualdade econômica. O estudo da desigualdade de gênero, à luz da desigualdade de classe, representa uma forma, ainda que parcial, de introduzir a questão mais geral da estrutura da desigualdade econômica na interpretação da desigualdade baseada nos atributos de gênero das pessoas.

Hipótese 1. Tendo em vista a tese geral marxista do reforço mútuo das formas de opressão de classe e aquelas não baseadas em classe, pretende-se investigar a hipótese de que as mulheres, em comparação aos homens, estariam relativamente mais representadas nas categorias de classe exploradas e economicamente oprimidas, e relativamente menos representadas nas localizações de classe privilegiadas. Para essa finalidade, será aferida a distribuição geral de gênero dentro das categorias de classe desigualmente recompensadas e entre elas. Serão estimados índices de representação de gênero para as diferentes categorias de classe. Esse índice mostra o quanto um grupo está representado em uma categoria em comparação à sua representação global na população ocupada. A paridade perfeita de representação equivale a 1, e o índice varia para menos ou mais conforme o sentido da desproporção (Sokoloff, 1992:30 e 69).

Hipótese 2. Classe social apresenta-se como uma variável moderadora ao estabelecer as condições que qualificam a associação entre a variável independente focal gênero e a variável dependente renda. Pretende-se investigar a hipótese da relevância do papel moderador da esfera da desigualdade de classe, em relação aos efeitos de gênero na renda, considerando o impacto das posições de classe constituídas, com seus mecanismos geradores de renda característicos, na acentuação ou atenuação da distância de renda associada aos atributos de gênero.

A análise da intensidade e da composição da desigualdade de gênero de renda no Brasil será realizada estimando-se a distância de gênero em sucessivos modelos lineares generalizados, que incluem outros fatores com impacto importante na renda e que podem estar associados às divisões de gênero. O uso desses "experimentos estatísticos" permite conhecer os principais fatores mediadores da desigualdade de gênero e estabelecer os efeitos diretos, e não mediados, das divisões de gênero. 
Dessa maneira, é possível distinguir entre a desigualdade de gênero que emerge devido ao acesso ou à alocação desigual de homens e mulheres em posições, recursos ou contextos que afetam a renda e aquela que resulta das recompensas desiguais atribuídas aos grupos de gênero inseridos nas mesmas circunstâncias sociais. A medida apropriada da distância de gênero depende do propósito da análise. Este estudo abarca o conjunto da estrutura social, e não apenas o mercado de trabalho. A diferença de gênero de renda estimada aqui, variável na dimensão e no significado conforme o modelo usado, reflete diversas formas de desvantagem de gênero; não apenas aquelas que ocorrem no âmbito da inserção no mundo do trabalho mas também as conseqüências decorrentes de escolhas e trajetórias empreendidas sob a influência de constrangimentos vividos ou antecipados (Gunderson, 1989:48-49). Os diversos modelos não controlam estatisticamente os fatores que expressam, nas relações de parentesco, as discrepâncias categóricas de gênero, como condição na família e presença de filhos menores. Dado o objetivo deste estudo, não teria sentido controlar o próprio efeito do condicionamento de gênero.

Estabelecidos a existência e o montante da distância de gênero, o foco da análise dirige-se para o papel moderador dos contextos de classe na diferença de gênero de renda, ou seja, a contribuição dessa fonte interativa ou multiplicativa específica da desigualdade de gênero. Segundo Hoyle e Robinson,

moderadores são variáveis que representam constructos propostos para aumentar, atenuar, cancelar ou reverter a associação entre duas variáveis. Moderação estatística pode tomar diferentes formas, mas a característica definidora de um efeito moderador é que a associação entre a variável independente e a variável dependente difere em força ou forma a diferentes níveis [ou categorias] do moderador (2004:213-214).

Visando remover uma fonte de heterogeneidade interna às categorias de classe, no modelo interativo será controlada a segregação ocupacional de gênero por meio de uma medida de composição de gênero das ocupações.

Escolha do modelo estatístico e da forma funcional do rendimento. Na análise de regressão da desigualdade de rendimento - uma variável contínua e positiva -, geralmente se realiza a escolha entre usar uma especificação linear ou uma especificação semilogarítmica da equação de regressão. Na especificação linear, a variável dependente representa o rendi- 
mento em valor monetário original; na semilogarítmica, o logaritmo natural do rendimento. A presente investigação beneficia-se da proposição metodológica formulada pelo professor Trond Petersen, da Universidade da Califórnia-Berkeley, que retém a vantagem interpretativa da especificação semilogarítmica, em termos de diferenças relativas de rendimento médio, mas que evita o problema inerente à transposição dos resultados para a forma original da variável dependente (Petersen, 2006; Goodman, 2006).

Sabe-se que os resultados da regressão sumarizam um aspecto específico da distribuição condicional da variável dependente dada a especificação do modelo. A especificação linear compara a média aritmética da variável não transformada, enquanto a semilogarítmica compara a média aritmética do logaritmo da variável. Entretanto, na especificação semilogarítmica, após a aplicação do antilog ou exponencial, visando converter de volta os valores para a métrica original, os valores assim obtidos passam a corresponder às diferenças relativas em termos de médias geométricas. As divergências entre as médias aritmética e geométrica podem transformar uma relação 0 (ou positiva) em uma relação negativa e vice-versa. Os coeficientes já convertidos da especificação semilogarítmica não podem mais ser interpretados como diferenças relativas nos rendimentos médios entre as categorias. Entretanto, uma breve amostragem de jornais de economia e de sociologia, realizada por Petersen, mostra que isso não é incomum, antes, parece representar a norma. Uma especificação loglinear de um Modelo Linear Generalizado (Generalized Linear Model), defendida pelo professor, produz interpretações de diferenças relativas em termos de médias aritméticas, que são a medida de interesse comum nesse tipo de estudo (Petersen, 2006; Goodman, 2006).

O presente estudo utilizará uma especificação exponencial ou multiplicativa do Modelo Linear Generalizado, com uma distribuição Gamma e uma função de ligação logarítmica (Petersen, 2006). A distribuição Gamma é apropriada quando a distribuição do erro é positivamente assimétrica em vários graus. Todos os modelos lineares generalizados foram estimados usando o programa estatístico Stata, versão 9.2 (Stata, 2005). Os coeficientes da especificação loglinear fornecem diferenças relativas entre as categorias e, por isso, ajustam-se bem à lógica teórica do estudo da desigualdade. Essa especificação, além disso, ajuda a corrigir a forte assimetria positiva da distribuição e contribui para 
reduzir a influência na estimativa dos valores extremos dissonantes do conjunto.

Características do Modelo Linear Generalizado. O Modelo Linear Generalizado permite trabalhar com dados em que a média da variável dependente é uma função não-linear dos parâmetros de regressão e a variável dependente não é normalmente distribuída. Ele separa a distribuição do erro da função de ligação e permite estender o modelo de regressão padrão de dois modos diferentes: escolhendo uma distribuição do erro não-normal e usando uma função de ligação não-linear. Isso representa uma inegável vantagem em relação à simples transformação da variável dependente em um modelo linear padrão, pois esta assume que a distribuição do erro é normal na escala transformada. O modelo lida sem problemas com distribuições de probabilidade do erro que não seguem uma forma normal e podem ser expressas na forma exponencial. Ele assume que uma função da média, em vez da própria média, é a função linear das variáveis independentes. A função de ligação é a transformação da média da variável dependente de modo que essa variável transformada seja uma função linear dos parâmetros da regressão (Dunteman e Ho, 2006). No modelo de regressão padrão, usado nos estudos de determinação de renda, a simples transformação logarítmica da variável dependente cria um inconveniente problema de interpretação. Os valores ajustados, assim como os parâmetros estimados, estão todos, em termos de resposta, em logaritmo. Uma abordagem melhor é internalizar dentro do próprio modelo a transformação logarítmica da variável dependente. No Modelo Linear Generalizado, a função de ligação logarítmica exponencializa o preditor linear em vez de fazer a transformação logarítmica da variável dependente. Tal procedimento, implícito no algoritmo do modelo, permite fácil interpretação dos parâmetros estimados, assim como dos valores ajustados (Hardin e Hilbe, 2007:74).

A questão das horas trabalhadas. Na especificação da equação de rendimentos para estimar a distância de gênero, o tratamento das horas trabalhadas exerce um papel bastante importante. Os rendimentos derivados da atividade de trabalho são considerados, na ótica mais influente da investigação econômica e sociológica, o produto de todas as horas trabalhadas e da taxa de rendimento média. Conforme tal enfoque, a equação rendimento $=$ horas trabalhadas * taxa de rendimento hora especifica a relação estrutural entre horas trabalhadas, rendimento hora e desigualdade de rendimento da atividade de trabalho $(\mathrm{Wu}$, 
2002:8-10). Uma especificação usual na literatura de estudos de recompensa computa a taxa de rendimento implícita dos dados de rendimento e tempo de trabalho. A variável dependente fica expressa como taxa de rendimento horário $=$ rendimento / horas trabalhadas, que representa uma equação equivalente à anterior. Entretanto, essa equação de rendimento padrão implicitamente assume uma taxa de rendimento constante independentemente do número de horas trabalhadas. O coeficiente das horas trabalhadas não é estimado; ele é constrangido a ser igual a 1. A suposição, ao usar o rendimento hora, é que a recompensa em determinado período é uma função linear das horas trabalhadas (Morgan e Arthur, 2005:383-385). Essa questão possui uma importância especial para a estimativa da diferença de gênero, já que a distribuição das horas trabalhadas varia significativamente entre homens e mulheres.

Supondo-se que o retorno relativo para as horas trabalhadas adicionais diminua com o incremento das horas, a penalidade de recompensas das mulheres será subestimada, uma vez que elas trabalham menos horas do que os homens. Uma especificação mais apropriada é usar o log dos rendimentos como variável dependente e o log do tempo trabalhado como variável independente de controle. Além disso, de modo complementar, cabe permitir que o retorno para o equivalente em log das horas trabalhadas varie de modo seccional (piecewise), em uma função spline, através do espectro de horas trabalhadas (ibidem:398-401). Uma spline linear possui valores especificados para um número finito de partes em que seu domínio é dividido e consiste de segmentos ligados suavemente nos pontos de junção $(k n o t)^{2}$. As variáveis correspondentes aos segmentos da spline linear foram criadas por meio do comando mkspline do programa estatístico Stata, versão 9.2. Uma spline linear estima a relação entre $y$ e $x$ como uma função composta de segmentos lineares (Stata, 2005).

Tratamento dos efeitos interativos. Cada variável envolvida em termos interativos possui diferentes efeitos que dependem do nível das outras variáveis com as quais ela interage. Diferentemente do coeficiente de $x$ em um modelo linear aditivo, os efeitos de $x$ em $y$ não são constantes em um modelo interativo; variam dependendo dos coeficientes de $x$ e $x z$, assim como do valor de $z$. Isso significa que o peso e o sinal do efeito de $x$ podem depender criticamente do valor fixado da outra variável, $z$, $\mathrm{e}$ vice-versa. No modelo interativo, o efeito de $x$ fornece o efeito estima- 
do da mudança em uma unidade de $x$, mantendo a variável $z$ fixa em 0 . O efeito de $x$ em $y$, dado $z=0$, é muito diferente do efeito de $x$ em $y$, controlando a variabilidade associada ao terceiro fator, $z$, que existe no modelo linear aditivo de regressão. Em se tratando de variáveis contínuas, esse tipo de especificação pode não fazer muito sentido, particularmente se não existem situações no mundo real em que a variável condicionante seja realmente 0 . Esse problema cria a necessidade de calcular efeitos marginais e erros padrões que tenham um significado substantivo. O pesquisador pode calcular os valores preditos de $y$ usando valores variáveis de $x$, mantendo constante $z$ em determinado valor significativo, como o valor médio ou outro valor interessante (Kam e Franzese, 2007:18-27; Brambor, Clark e Golder, 2006:73-74).

Quando são construídos termos interativos entre variáveis binárias, como classe social e gênero, a interpretação dos coeficientes estimados exige menos trabalho, pois o efeito condicional ao valor 0 refere-se naturalmente à categoria de referência (omitida) da outra variável que compõe o termo interativo. Na perspectiva da presente investigação, gênero representa a variável independente focal qualitativa; classe, a variável moderadora qualitativa. A análise das variações da distância de gênero, conforme as categorias de classe, utilizará a estratégia de "recodificação das variáveis binárias", em que são realizados sucessivos recálculos da equação de regressão e produzidas estatísticas relevantes, após a especificação de cada categoria de referência de interesse (o efeito condicional ao valor 0) (Jaccard e Turrisi, 2003:55-60).

Base de dados. A pesquisa quantitativa utiliza a base de microdados da PNAD/Instituto Brasileiro de Geografia e Estatística - IBGE de 2005. A PNAD é realizada por meio de uma amostra probabilística de domicílios obtida em três estágios de seleção: municípios, setores censitários e unidades domiciliares. O levantamento abarca o conjunto do território brasileiro (IBGE, 2006). A amostra utilizada neste estudo é composta de 165.147 casos, que possuem informações válidas para todas as variáveis. Em virtude da escolha da especificação loglinear de um Modelo Linear Generalizado, a análise foi restrita aos casos com renda positiva. Utiliza-se apenas a renda do trabalho principal, por motivo de ajuste, já que a classificação socioeconômica usada para mensurar o conceito de classe social foi construída com base no trabalho principal da pessoa. 


\section{CLASSE SOCIAL E DISTÂNCIA DE GÊNERO DE RENDA}

O confronto das diferenças de renda média entre homens e mulheres conforme as categorias de classe -, oferecido pela Tabela 1, serve para introduzir uma abordagem de classe da diferença de gênero de renda. Essa incursão inicial visa basicamente detectar padrões relevantes, ainda que provisórios, pois a produção de evidências empíricas mais sólidas envolve a introdução da análise de regressão. Vejamos primeiramente os contextos que mais exacerbam a distância de gênero de renda. Essa distância se revela extremamente pronunciada entre os conta-próprias precários $(75,64 \%)$, em que a presença feminina ocorre em elevada proporção (44\%). A inserção das mulheres nessa categoria destituída, que representa $10,8 \%$ do conjunto da estrutura social, intensifica fortemente sua penalidade de gênero. Uma distância ainda maior ocorre entre os conta-próprias agrícolas (107,03\%); porém, há aí uma incidência muito reduzida de mulheres como titulares desse tipo de empreendimento $(11,9 \%$ ) (ver, na Tabela 2 , a distribuição de gênero das categorias de classe).

Tabela 1

Renda Média Mensal (em Real) do Trabalho Principal das Categorias de Classe conforme Gênero, Diferença Percentual a Favor dos Homens e Renda Média Geral, para os Casos com Renda Positiva - Brasil, 2005

\begin{tabular}{l|c|c|c|c}
\hline Categorias de Classe por Gênero & Homens & Mulheres & $\begin{array}{c}\text { \% a favor dos } \\
\text { Homens }\end{array}$ & Média Geral \\
\hline Capitalista & $5.640,60$ & $3.666,10$ & 53,86 & $5.161,02$ \\
Pequeno empregador & $1.989,61$ & $1.686,16$ & 18,00 & $1.910,91$ \\
Conta-própria não-agrícola & 984,52 & 637,02 & 54,55 & 888,45 \\
Conta-própria agrícola & 380,42 & 183,75 & 107,03 & 357,09 \\
Especialista autônomo & $3.447,06$ & $2.430,48$ & 41,83 & $3.036,17$ \\
Gerente & $2.352,27$ & $1.651,07$ & 42,47 & $2.084,32$ \\
Empregado especialista & $2.762,77$ & $1.863,25$ & 48,28 & $2.285,22$ \\
Empregado qualificado & $1.182,51$ & 822,60 & 43,75 & 983,47 \\
Supervisor & $1.061,05$ & 967,90 & 9,62 & $1.042,72$ \\
Trabalhador típico & 644,59 & 504,56 & 27,75 & 592,14 \\
Trabalhador elementar & 334,11 & 323,13 & 3,40 & 331,92 \\
Conta-própria precário & 503,73 & 286,80 & 75,64 & 408,48 \\
Empregado doméstico & 356,59 & 265,57 & 34,27 & 271,65 \\
\hline Total & $\mathbf{8 6 9 , 0 2}$ & $\mathbf{6 1 8 , 3 1}$ & 40,55 & $\mathbf{7 6 8 , 9 7}$ \\
\hline
\end{tabular}

Fonte: IBGE, 2006 (tabulações especiais; ver Quadro 1 do Anexo). 
Entre os empregadores, a diferença de gênero aparece alta para os capitalistas, mas bem menor para os pequenos empregadores, categoria em que há menos capitalização e mais personalização do empreendimento, o que sinaliza um padrão oposto ao manifestado no efeito de classe na distância de raça (Figueiredo Santos, 2005b; 2006a). Já a categoria de conta-própria não-agrícola apresenta um patamar de distância similar ao dos capitalistas, apesar das marcantes diferenças no montante e na natureza do controle de ativos de capital.

Entre os empregados, a diferença mostra-se particularmente elevada entre os assalariados de classe média, ou seja, empregados especialistas e gerentes. Já nas situações ambíguas de classe de empregados qualificados e supervisores, existe um contraste entre a numericamente importante categoria de empregados qualificados, com elevada distância de gênero (43,75\%), e a situação da pequena categoria de supervisores $(9,62 \%)$.

No universo dos trabalhadores sem exercício de autoridade e sem qualificação diferenciada, cabe contrastar a distância significativa registrada entre os trabalhadores típicos $(27,75 \%)$ - abaixo da diferença média $(40,55 \%)$ - e a diferença ínfima entre os trabalhadores elementares $(3,40 \%)$, que formam um pólo fortemente destituído no interior do trabalho assalariado. A distância aparece com força entre os empregados domésticos $(34,27 \%)$, categoria em que existem pouquíssimos homens $(6,7 \%)$, mostrando uma elevada diferença de gênero nesse terreno francamente feminino. Cabe considerar, no entanto, o que vai ocorrer com esses padrões com a introdução dos controles estatísticos realizados pela análise de regressão.

Interseções entre classe e gênero. A Tabela 2 retrata a distribuição diferenciada de homens e mulheres nas categorias de classe e introduz a questão da desigualdade de alocação no mundo das classes sociais ou de acesso de gênero a esse mundo. As mulheres estão em clara minoria entre os controladores de ativos de capital, em seus vários graus e tipos, do capitalista à categoria de conta-própria não-agrícola, mas já representam uma minoria relevante. Entretanto, ao contrário do que ocorre com as divisões de raça, retratadas em Figueiredo Santos (2005b; 2006a), não existe um bloqueio muito forte no acesso a ativos maiores de capital, tipificados na categoria de capitalistas. 
Tabela 2

Distribuição Percentual de Mulheres e Homens entre e dentro das Categorias de Classe (entre parênteses) e Índice de Representação das Mulheres - Brasil, 2005

\begin{tabular}{l|c|c|c|c}
\hline Categorias de Classe & Total & Homem & Mulher & Índice* $^{*}$ \\
\hline Capitalista & 0,6 & $0,7(75,6)$ & $0,4(24,4)$ & 0,61 \\
Pequeno empregador & 3,9 & $4,8(74,1)$ & $2,6(25,9)$ & 0,65 \\
Conta-própria não-agrícola & 7,1 & $8,5(72,3)$ & $4,9(27,7)$ & 0,69 \\
Conta-própria agrícola & 5,6 & $8,2(88,1)$ & $1,7(11,9)$ & 0,30 \\
Especialista autônomo & 1,1 & $1,1(59,7)$ & $1,1(40,3)$ & 1,01 \\
Gerente & 2,8 & $2,9(61,8)$ & $2,7(38,2)$ & 0,96 \\
Empregado especialista & 3,7 & $2,9(47,0)$ & $4,9(53,0)$ & 1,33 \\
Empregado qualificado & 7,4 & $5,5(44,8)$ & $10,3(55,2)$ & 1,38 \\
Supervisor & 1,8 & $2,4(80,2)$ & $0,9(19,8)$ & 0,49 \\
Trabalhador típico & 34,8 & $36,3(62,6)$ & $32,7(37,4)$ & 0,94 \\
Trabalhador elementar & 11,7 & $15,7(79,9)$ & $5,9(20,1)$ & 0,50 \\
Conta-própria precário & 10,8 & $10,0(56,0)$ & $11,8(44,0)$ & 1,10 \\
Empregado doméstico & 8,7 & $1,0(6,7)$ & $20,3(93,3)$ & 2,34 \\
\hline Total & $\mathbf{1 0 0 , 0}$ & $\mathbf{1 0 0 , 0 ( 6 0 , 1 )}$ & $\mathbf{1 0 0 , 0 ( 3 9 , 9 )}$ & $\mathbf{1 , 0 0}$ \\
\hline
\end{tabular}

Fonte: IBGE, 2006 (tabulações especiais; ver Quadro 1 do Anexo). Dados para os casos com renda positiva.

* O Índice de Representação mostra o quanto as mulheres estão representadas em uma categoria em comparação à sua representação total (39,9\%).

As mulheres inserem-se fortemente em posições privilegiadas ou mais vantajosas na ordem de classe através do controle de ativos de qualificação e perícia, como pode ser constatado por meio de sua representação entre as categorias de empregados especialistas, especialistas autônomos e empregados qualificados. $\mathrm{Na}$ dimensão de exercício de autoridade, as mulheres atingem uma presença expressiva $(38,2 \%)$ praticamente casada com sua inserção geral na estrutura social - na importante categoria de gerentes, o que mostra sua ascensão aos escalões de poder do mundo das organizações empregadoras e do Estado. Já sua participação na categoria de supervisores se mostra bem débil $(19,8 \%)$, o que pode estar associado ao papel da indústria de transformação na reprodução dessa categoria de classe $^{3}$.

A classe trabalhadora típica mostra uma composição feminina mais destacada (37,4\%), perto do índice de equilíbrio, quando comparada à sua participação global na população com posição de classe assinalada $(39,9 \%)$. Os trabalhadores elementares, categoria em que predominam 
as atividades manuais agrícolas e não-agrícolas, revelam uma presença feminina bem minoritária $(20,1 \%)$. Na verdade, entre os segmentos economicamente oprimidos, as mulheres concentram-se mais nas categorias de conta-próprias precários e empregados domésticos, que totalizam 32,1\% das posições de classe do gênero feminino (distribuição entre as categorias de classe na Tabela 2).

A distribuição de gênero entre as categorias agregadas de classe, feita na Tabela 3, mostra que as mulheres possuem um acesso mais difícil, mas ainda assim ponderável (25,7\%), ao controle de ativos de capital. Em decorrência particularmente da pequena representação das mulheres entre os conta-próprias agrícolas, a pequena burguesia nãoagrícola e agrícola possui uma feição menos feminina (20,7\%). Já no grande agregado formado pelos trabalhadores, empregados qualificados e supervisores, as mulheres estão em situação de equilíbrio, considerando seu peso global entre as posições constituídas, conforme captado pelo índice de representação. Fica patente a polarização de classe existente no universo feminino quando são confrontadas as distribuições das mulheres nos agregados de classe média e de trabalhadores fortemente destituídos. As mulheres sobrepujam os homens no relativamente reduzido $(7,6 \%)$, mas fortemente privilegiado agregado de classe média, considerando a distribuição de gênero entre as categorias de classe $(8,7 \%$ contra $6,8 \%)$. Além disso, a representação feminina

Tabela 3

Distribuição Percentual de Homens e Mulheres entre e dentro das Categorias Agregadas de Classe (entre parênteses) e Índice de Representação das Mulheres - Brasil, 2005

\begin{tabular}{|c|c|c|c|c|}
\hline Categorias Agregadas de Classe & Total & Homem & Mulher & Índice* \\
\hline Capitalista e pequeno empregador & 4,5 & $5,6(74,3)$ & $2,9(25,7)$ & 0,64 \\
\hline Conta-própria não-agrícola e agrícola & 12,7 & $16,8(79,3)$ & $6,6(20,7)$ & 0,52 \\
\hline $\begin{array}{l}\text { Gerente, empregado especialista e es- } \\
\text { pecialista autônomo }\end{array}$ & 7,6 & $6,8(54,2)$ & $8,7(45,8)$ & 1,15 \\
\hline $\begin{array}{l}\text { Trabalhador típico, empregado quali- } \\
\text { ficado e supervisor }\end{array}$ & 44,0 & $44,1(60,3)$ & $43,8(39,7)$ & 1,0 \\
\hline $\begin{array}{l}\text { Trabalhador elementar, doméstico e } \\
\text { conta-própria precário }\end{array}$ & 31,2 & $26,6(51,3)$ & $38,0(48,7)$ & 1,22 \\
\hline Total & 100,0 & $100,0(60,1)$ & $100,0(39,9)$ & 1,00 \\
\hline
\end{tabular}

Fonte: IBGE, 2006 (tabulações especiais; ver Quadro 1 do Anexo). Dados para os casos com renda positiva.

* O Índice de Representação mostra o quanto as mulheres estão representadas em uma categoria em comparação à sua representação total (39,9\%). 
dentro do agregado de classe média $(45,8 \%)$ ultrapassa seu peso global $(39,9 \%)$, o que não ocorre com os homens. Por outro lado, a distribuição de gênero entre as categorias de classe demonstra que $38 \%$ das mulheres, contra apenas $26,6 \%$ dos homens, se inserem na ordem de classe como trabalhadoras elementares, empregadas domésticas e conta-próprias precárias, que possuem uma densidade social bem maior em comparação aos estratos de classe média.

A Tabela 4 permite comparar as manifestações da distância de classe de renda nos universos masculino e feminino. Constata-se, em primeiro lugar, a forte dominância da desigualdade de classe em relação à desigualdade de gênero, pois o padrão constituído pelo ordenamento de classe revela-se marcante e análogo em ambos os universos de gênero. Entretanto, os dados mostram igualmente uma incidência um tanto menos acentuada das assimetrias de classe entre as mulheres, ao serem

Tabela 4

Diferenças Percentuais de Classe na Renda do Trabalho Principal, entre as Categorias Designadas de Classe e a Categoria de Referência (omitida) de Trabalhador Elementar, para Homens, Mulheres e em Geral, Estimadas por Modelo Linear Generalizado

\begin{tabular}{l|c|c|c}
\hline $\begin{array}{l}\text { Categorias Designadas de Classe } \\
\text { por Gênero }\end{array}$ & $\begin{array}{c}\text { Diferença en- } \\
\text { tre Homens } \\
\mathbf{( \% )}\end{array}$ & $\begin{array}{c}\text { Diferença en- } \\
\text { tre Mulheres } \\
\mathbf{( \% )}\end{array}$ & $\begin{array}{c}\text { Diferença } \\
\text { Geral } \\
\mathbf{( \% )}\end{array}$ \\
\hline Capitalista & 584,35 & 454,35 & 550,13 \\
Pequeno empregador & 216,82 & 213,02 & 216,92 \\
Conta-própria não-agrícola & 75,84 & 50,28 & 68,53 \\
Conta-própria agrícola & 4,03 & $-22,20$ & $0,66^{*}$ \\
Especialista autônomo & 207,00 & 186,88 & 204,24 \\
Gerente & 171,70 & 127,57 & 157,76 \\
Empregado especialista & 168,92 & 127,85 & 155,25 \\
Empregado qualificado & 80,76 & 41,42 & 64,03 \\
Supervisor & 76,36 & 70,62 & 73,62 \\
Trabalhador típico & 33,01 & 19,06 & 29,32 \\
Conta-própria precário & 14,00 & 6,60 & 7,03 \\
Empregado doméstico & $2,21^{*}$ & 5,33 & 3,88 \\
\hline
\end{tabular}

Fontes: Tabela 1-A, modelo 8, para a diferença de classe geral e Tabela 3-A para homens e mulheres, ambas do Anexo Estatístico.

Nota: Modelo Linear Generalizado usando a distribuição Gamma e a função de ligação log, com todas as variáveis, exceto a composição ocupacional de gênero (equivalente ao modelo 8).

A expressão do impacto percentual dos coeficientes foi calculada conforme 100 [exp (coef.) -1].

* Coeficiente estatisticamente não-significativo. 
consideradas as vantagens de renda das categorias designadas de classe em relação à categoria de referência (omitida) de trabalhador elementar, com o controle estatístico de um leque amplo de fatores, quais sejam: alocação de gênero na ordem de classe, raça, educação, anos de trabalho, anos no trabalho principal, região geográfica, status de migração, residência urbana/rural, setor privado/público e seis grandes setores econômicos.

Dimensão e composição da distância de gênero de renda. Na análise de regressão aplicada a dados observacionais, o êxito do empreendimento depende, na maioria das vezes, justamente da definição das variáveis a serem incluídas no modelo estatístico. A diferença de gênero de renda será investigada através de uma abordagem seqüencial ou hierárquica, em que as variáveis independentes relevantes são acrescentadas cumulativamente em uma ordem predeterminada pela estratégia analítica (Cohen et alii, 2003:158-162). O método hierárquico permite que o pesquisador tenha maior controle sobre o modelo de regressão e explore relações causais entre as variáveis conduzindo o que seriam "experimentos estatísticos" (De Vaus, 2002:362-365). Os vários modelos de regressão são sucessivamente abrangentes, ou seja, as novas variáveis são acrescentadas mantendo-se as anteriores. Parte-se da distância bruta de gênero, não controlada, e procura-se perscrutar a relação original entre gênero e renda considerando os diversos fatores relevantes que intersectam, afetam ou compõem a relação original. Utiliza-se o conceito de coeficiente parcial de regressão com o objetivo de medir o impacto da variável independente gênero na variável dependente renda, após a remoção da influência de outras variáveis relevantes. A utilização dessa noção permite olhar a estrutura subjacente aos dados a fim de trazer à superfície determinados padrões não imediatamente óbvios, que indicam as relações mais profundas entre as variáveis (Mukherjee, White e Wuyts, 1998:170-173). Os ensinamentos oferecidos pela "matemática dos controles" podem ser estendidos para a análise da regressão e para o entendimento do controle estatístico que ela opera. As diferentes formas de controle, como a realizada pela "classificação de subgrupos" em tabelas de contingência ou o coeficiente parcial de regressão, são similares em sua função: “Elas são diferentes expressões de um único princípio: controle significa controle da variância" (Pedhazur, 1982:98). A relação original entre as variáveis gênero e renda envolve o complexo conjunto de associações parciais que a constituem, em que entram correntes e contracorrentes. Essas associações parciais ou contingentes, formadas pelas associações de gênero e ren- 
da com outras variáveis, combinam-se de várias maneiras para gerar a relação observada e podem operar em diferentes direções no interior do nexo estabelecido entre as duas variáveis (Rosenberg, 1976:281282). A Tabela 5 apresenta as estimativas da distância de gênero de renda entre homens e mulheres, conforme os diversos modelos estimados, sendo que os coeficientes de regressão aparecem já convertidos em diferenças percentuais a favor dos homens ${ }^{4}$.

O modelo 1, sem nenhuma variável independente de controle, constata uma diferença bruta de renda de $39,01 \%$ a favor dos homens. Esse modelo, no entanto, não distingue a desigualdade de renda formada propriamente pelas diferenças nas "taxas" de recompensa econômicas obtidas daquela derivada das diferenças de horas trabalhadas entre os grupos. Em se tratando das divisões de gênero, cabe considerar de modo especial esses dois mecanismos distintos de geração de desigualdade de renda (Birkelund, 1992:55).

\section{Tabela 5}

Diferença Percentual de Renda do Trabalho Principal a Favor do Homem, em Relação à Mulher, Estimada através de Modelo Linear Generalizado - Brasil, 2005

\begin{tabular}{l|c}
\hline Modelo & $\begin{array}{c}\text { Distância de Renda } \\
\text { (\%) }\end{array}$ \\
\hline 1 (gênero) & 39,01 \\
2 (+ horas de trabalho: spline linear)* & 31,85 \\
3 (+ raça) & 33,49 \\
4 (+ educação) & 52,54 \\
5 (+ tempo de trabalho e tempo no trabalho atual) & 43,43 \\
6 (+ região, residência urbana e migrante) & 46,52 \\
7 (+ setor público e seis grandes setores econômicos) & 44,77 \\
8 (+ categorias de classe) & 35,16 \\
9 (+ composição de gênero das ocupações) & 27,26 \\
\hline
\end{tabular}

Fonte: Tabela 1-A do Anexo Estatístico.

Notas: Modelo Linear Generalizado usando a distribuição Gamma e a função de ligação log.

* Spline linear do equivalente em log dos intervalos de horas de trabalho.

O impacto percentual dos coeficientes foi calculado conforme: 100 [exp (coef.) -1]

O modelo 2 introduz o controle das diferenças de horas trabalhadas (spline linear), o que reduz a distância de gênero bruto para $31,85 \%$, ou seja, desaparece quase um quinto da diferença original. Isso significa que uma parte da desigualdade de gênero, ao ser considerado o trabalho principal dos indivíduos, ocorre sob a forma de diferenças no mon- 
tante de engajamento nas atividades de trabalho devido aos condicionamentos de gênero, como revelado pelas diferenças de horas trabalhadas. A introdução da spline linear comprova a proposição de que a taxa de rendimento hora não pode ser tratada como uma constante. Em todos os modelos, a taxa de recompensa por hora varia claramente conforme o espectro de horas trabalhadas. O modelo 8, reproduzido na Tabela 1-A do Anexo Estatístico, que possui todos os controles, exceto a composição ocupacional de gênero, mostra um coeficiente de regressão (em log) de 0,2785 para a faixa de 1 a 29 horas por semana; de 0,8932 para a faixa de 30 a 39 horas; de apenas 0,2003 para a faixa de 40 a 49 horas; e de 0,3083 para a faixa de 50 ou mais horas ${ }^{5}$. Os coeficientes spline representam a inclinação da relação entre o rendimento e a hora trabalhada para cada faixa de horas trabalhadas. A título de comparação, na especificação de rendimento hora, que não foi usada aqui, é como se todos os coeficientes spline implícitos tivessem um multiplicador do termo de horas constrangido a 1. Na especificação spline da equação, ao contrário, o rendimento do indivíduo é uma função das diversas variáveis de controle, das horas trabalhadas e do termo de erro. Se os coeficientes spline fossem constrangidos a 1, como ocorre na especificação de rendimento hora, o multiplicador do termo de horas seria igual às horas trabalhadas, fazendo do rendimento o produto simples da taxa de rendimento e das horas trabalhadas (Morgan e Arthur, 2005:396-398). Note-se que apenas na faixa de 30 a 39 horas o rendimento aumenta a uma taxa próxima de 1 , ou seja, o rendimento está mais diretamente vinculado às horas de trabalho. Nas demais faixas, embora o rendimento aumente com as horas de trabalho, isso ocorre a uma taxa mais reduzida. Considerando que as mulheres estão mais presentes nas faixas de horas trabalhadas com taxa de rendimento hora maior, conforme descrito na nota 5, esse resultado demonstra que a introdução do rendimento mensal como variável dependente e do log das horas trabalhadas como variável independente de controle evita a subestimação da distância de gênero de renda. A utilização do rendimento hora como variável dependente em um Modelo Linear Generalizado, não mostrado aqui, similar ao modelo 8 , reduz a estimativa da vantagem masculina para apenas $21,29 \%$. Note-se que esse grau tão grande de discrepância entre as especificações foi apontado no inovador trabalho metodológico de Morgan e Arthur (2005), no qual se respalda o tratamento adotado aqui ${ }^{6}$.

O controle dos efeitos das divisões de raça, acrescentado no modelo 3 , faz com que a diferença de gênero aumente. Cabe preliminarmente de- 
finir que efeitos estão sendo controlados. O modelo "remove" da distância de gênero os efeitos da distribuição diferenciada dos gêneros entre os grupos raciais e das diferenças de recompensa entre os grupos raciais. Na especificação do modelo de regressão 3, em que são considerados apenas os efeitos aditivos entre as variáveis, os diferenciais de renda a favor dos brancos seriam equivalentes para homens e mulheres (Hardy, 1993:25-26). Cabe considerar, no entanto, os "efeitos de composição" entre as variáveis. As mulheres possuem uma representação privilegiada no grupo racial branco $(49,87 \%)$, superior à representação dos homens (46,36\%). Visto que os brancos possuem enorme vantagem de renda sobre os não-brancos (ver modelo 3 na Tabela 1-A do Anexo Estatístico), com exceção da ínfima categoria de amarelos, na qual existem também mais mulheres, ao ser controlado o efeito da maior inserção direta das mulheres brancas na ordem de classe, ocorre, como seria de se esperar, uma ampliação da diferença de gênero de renda a favor dos homens ${ }^{7}$.

O controle estatístico realizado no modelo 4 , das diferenças de educação, faz com que a distância de gênero salte para 52,54\%. Cabe precisar em que consiste o controle estatístico da variável educação, que foi mensurada em quatro categorias, representando as transições mais importantes na aquisição de credenciais educacionais no Brasil: menos de 8 anos de educação (categoria de referência na regressão), 8 a 10 anos, 11 a 14 anos e 15 anos ou mais ${ }^{8}$. Controla-se o efeito na diferença de gênero de renda da desigualdade de educação entre os grupos de gênero e dos diferenciais de renda por nível educacional. Na especificação do modelo de regressão sem termos interativos entre gênero e educação, os diferenciais de renda por nível educacional seriam equivalentes para homens e mulheres ${ }^{9}$. Isso significa que o efeito produzido na distância de gênero de renda decorre, dados os diferenciais existentes de renda por nível educacional, da desigualdade de educação entre homens e mulheres. Sabe-se que no Brasil existe uma associação muito forte entre educação e renda em virtude, particularmente, da grande desigualdade de educação, ao lado dos diferenciais de renda por nível educacional (Figueiredo Santos, 2002:253-262). Supõe-se que a distância de renda entre homens e mulheres não se alteraria se a distribuição da educação e sua potência causal sobre a renda fossem neutras em relação ao gênero. Na medida em que parte da diferença de renda fosse mediada pela educação, deveria ocorrer uma redução dessa discrepância de gênero quando fosse introduzido o controle das credenciais educacionais. Esse não é o caso aqui, pois as mulheres pos- 
suem atualmente uma escolaridade maior do que a dos homens no Bra$\operatorname{sil}^{10}$. Ocorre então que a distância de gênero aumenta pronunciadamente à medida que o controle estatístico "remove" o efeito dessa vantagem de escolaridade das mulheres inseridas na ordem de classe. $\mathrm{O}$ controle da vantagem de escolaridade das mulheres, que representa um componente de acesso a um recurso valioso, serve para demonstrar ou realçar o peso da discriminação de valor de gênero, ou seja, do tratamento desigual que decorre do status da mulher como uma categoria socialmente construída, que não se exerce por meio de mecanismos mediadores.

As mulheres contam com uma educação maior, mas têm uma desvantagem de "anos de trabalho" e "anos no atual emprego". O controle desses fatores introduzidos no modelo 5 , ou seja, de sua desvantagem, faz com que a distância de gênero desça para $43,43 \%{ }^{11}$. Fazem-se sentir aqui os condicionamentos de gênero associados à maternidade, ao cuidado dos filhos pequenos, às definições de prioridades no âmbito de família e às exigências dos postos de trabalho, que comprometem a trajetória de engajamento no trabalho da mulher. A diferença de renda real seria de fato um tanto menor, pois o indicador usado em anos de trabalho não considera as interrupções de trabalho a que as mulheres estão mais sujeitas em virtude das responsabilidades familiares, o que possivelmente superestima a exposição da mulher à atividade de trabalho (Duncan, 1996:460).

O modelo 6 controla o efeito de obter renda em determinadas regiões, morar na área urbana ou rural e ser ou não um migrante (nascer ou não no município de residência). A distância de gênero de renda se eleva $3 \%$ devido ao controle estatístico de um "efeito de composição" favorável para a mulher, que expressa sua inserção na ordem de classe em regiões com renda média maior. Observe-se que esse modelo, ao considerar apenas a existência de "efeitos equivalentes", assume o pressuposto simplificador de que a distância de gênero seria idêntica em todas as regiões e que as diferenças regionais de renda seriam iguais para homens e mulheres. Entretanto, a investigação de "efeitos interativos ou não equivalentes" entre gênero e região vai além do escopo da presente investigação.

O modelo 7 controla os efeitos na renda associados com a inserção das pessoas nos seis grandes setores de atividade econômica e seu posicionamento na divisão entre setor público e privado. Cabe inicialmente 
fazer uma idéia clara de que efeitos estão sendo controlados estatisticamente na regressão. Nesse modelo, além das variáveis anteriores, estão sendo controlados dois novos tipos de efeito existentes na relação original entre as variáveis gênero e renda: distribuição diferenciada de gênero e diferenças de renda entre os setores. A título de exemplo, controlam-se nesse modelo tanto o efeito da distribuição desigual dos gêneros na divisão público/privado quanto o efeito da vantagem de renda de se estar no setor público. A redução em quase $2 \%$ da diferença de renda revela uma desvantagem de distribuição das mulheres entre os seis grandes setores econômicos. Elas estariam mais presentes em setores econômicos com rendas médias menores, embora possuam uma vantagem de acesso ao setor público ${ }^{12}$.

O modelo 8 introduz o controle de classe social nos dois sentidos do controle estatístico, ou seja, como "remoção" da relação original entre gênero e renda dos efeitos da composição de gênero das categorias de classe e das diferenças de recompensa entre as categorias de classe. De modo diferente dos modelos 3 a 7 , ocorre uma redução ponderável da distância de gênero. Essa situação revela o papel mediador de classe na distância de renda ao captar a parte da diferença de gênero que se exerce através da ordem de classe, ou seja, em virtude da alocação desigual de gênero entre as categorias de classe desigualmente recompensadas, de modo totalmente independente das demais variáveis. Naturalmente, parte do efeito mediador de classe pode já ter sido captado por outras variáveis anteriores, como educação, região e setor, pois existe uma associação desses fatores com a ordem de classe, de modo que as categorias de classe incluídas no modelo apareçam como uma nova fonte independente de variabilidade, não compartilhada pelas demais variáveis. O modelo 8 apresenta o que seria uma estimativa da distância líquida de gênero no Brasil para as pessoas situadas nas mesmas circunstâncias sociais de classe, educação, região, setor econômico etc.

O modelo 9 agrega o controle da composição de gênero das ocupações. A segregação ocupacional de gênero representa naturalmente uma fonte importante de desigualdade de alocação ou acesso presente na distância de gênero de renda. Em geral, só faz sentido introduzir como controle estatístico uma dimensão constituinte do fenômeno da discriminação de gênero, nesse caso, a desigualdade de alocação de gênero na ordem ocupacional, se esse procedimento ajudar a entender os componentes do fenômeno e os mecanismos por meio dos quais este gera efeitos na renda. A introdução dessa variável independente de contro- 
le visou remover o efeito específico da heterogeneidade ocupacional de gênero interna às categorias de classe. Esse último controle estatístico reduz a diferença de gênero, como seria de se esperar; porém, chama a atenção a persistência de uma elevada diferença de gênero $(27,26 \%)$, não mediada pela distribuição ocupacional de gênero.

Efeitos de classe na distância de gênero de renda. Investiga-se a partir deste ponto a influência dos contextos de classe na acentuação ou atenuação dos efeitos dos atributos de gênero na renda das pessoas. A Tabela 6 apresenta os resultados do Modelo Linear Generalizado, com as variáveis interativas entre classe e gênero, que estimam as "relações condicionais" entre gênero e renda ao especificar "as condições segundo as quais a relação original se fortalece ou se enfraquece" (Rosenberg, 1976:125). São apresentadas estimativas sem e com controle da composição ocupacional de gênero. Esse procedimento visa aferir e controlar as diferenças de composição interna de gênero das categorias de classe e produzir um resultado mais robusto. Pretende-se demonstrar, com isso, que o efeito estimado decorre do contexto comum de classe, não podendo ser atribuído aos padrões de composição de gênero dos grupos ocupacionais ou das subcategorias existentes dentro de cada categoria de classe. Tomemos o caso da categoria de gerentes. Existem diferentes níveis de gerência, e os gêneros podem estar distribuídos desigualmente, por exemplo, entre "executivos" e "gerentes operacionais". O controle da composição de gênero dos grupos ocupacionais de gerentes permite afirmar, com mais segurança, que a distância de gênero encontrada na categoria decorre da especificidade do mecanismo de exercício de dominação sobre ativos humanos, estando, portanto, dissociado do simples efeito de composição interna de gênero presente na categoria ampla de gerentes. Ao ser controlado o efeito da "composição ocupacional de gênero", torna-se mais robusta a conclusão de que o efeito em questão decorre do "contexto comum de classe" e do mecanismo gerador de renda característico da categoria. Nesse sentido, a parte principal da análise será feita considerando a diferença com o controle da composição ocupacional de gênero.

Constata-se uma elevada distância de gênero entre os capitalistas $(47,00 \%)$, mostrando a força da operação conjugada tanto da desigualdade de acesso de gênero, já mostrada na Tabela 2, quanto da desigualdade de tratamento revelada agora. Entre os empregadores, a distância de gênero aparece alta para os capitalistas e bem menor para os pequenos empregadores, o que sugeriria um padrão divergente da- 
quele registrado para a diferença de raça nessas categorias, em que a maior capitalização e a menor personalização do empreendimento parecem comprometer o poder gerador de efeitos dos mecanismos da discriminação racial (Figueiredo Santos, 2005b; 2006a). A distância de gênero de renda, por outro lado, não segue um padrão de relações condicionais com uma lógica claramente consistente em termos da dimensão de ativos de capital controlados. A menor distância existente entre os três tipos de portadores de recursos de capital está justamente na categoria intermediária de pequenos empregadores $(19,34 \%)$. Os conta-próprias não-agrícolas, como menos ativos de capital, registram uma diferença bem superior aos pequenos empregadores (31,48\%). O controle da composição ocupacional de gênero, como seria de se esperar, quase não afeta o valor original da distância entre capitalistas e pequenos empregadores, mostrando que o processo independe da especificação ocupacional do empregador.

Tabela 6

Diferenças Percentuais de Renda do Trabalho Principal a Favor do Homem, em Relação à Mulher, conforme as Categorias de Classe, sem e com Controle da Composição Ocupacional de Gênero - Brasil, 2005

\begin{tabular}{|c|c|c|}
\hline Categorias de Classe & $\begin{array}{c}\text { Distância de Renda sem } \\
\text { Controle da Composição } \\
\text { Ocupacional } \\
(\%)\end{array}$ & $\begin{array}{c}\text { Distância de Renda com } \\
\text { Controle da Composição } \\
\text { Ocupacional } \\
(\%)\end{array}$ \\
\hline Capitalista e fazendeiro & 46,24 & 47,00 \\
\hline Pequeno empregador & 19,90 & 19,34 \\
\hline Conta-própria não-agrícola & 38,60 & 31,48 \\
\hline Conta-própria agrícola & 58,40 & 58,68 \\
\hline Especialista autônomo & 26,76 & 23,68 \\
\hline Gerente & 41,43 & 41,03 \\
\hline Empregado especialista & 39,81 & 34,49 \\
\hline Empregado qualificado & 51,41 & 40,00 \\
\hline Supervisor & 22,66 & 18,27 \\
\hline Trabalhador típico & 32,33 & 22,63 \\
\hline Trabalhador elementar & 18,59 & 14,51 \\
\hline Conta-própria precário & 44,60 & 31,83 \\
\hline Empregado doméstico & 27,89 & 23,36 \\
\hline Geral & 35,16 & 27,26 \\
\hline
\end{tabular}

Fonte: Tabela 2-A do Anexo Estatístico.

Notas: Modelo Linear Generalizado usando a distribuição Gamma e a função de ligação log. O impacto percentual dos coeficientes foi calculado conforme: 100 [exp (coef.) -1]. 
A enorme diferença encontrada entre os conta-próprias agrícolas mostra que essa atividade se revela uma área inóspita para a presença da mulher como titular isolada ou uma dos titulares do empreendimento familiar, ou seja, cujo status no emprego garanta uma "retirada" de renda individualizada. Quando isso ocorre, por opção ou contingência (morte ou migração do cônjuge), o processo se faz em condições extremamente difíceis.

A distância de gênero de renda atinge um patamar elevado entre os empregos de classe média, particularmente entre os gerentes, mostrando que esses contextos oferecem um espaço maior ou um ambiente mais propício para a manifestação dos efeitos da divisão de gênero. $\mathrm{O}$ acesso das mulheres (majoritariamente as brancas) ao exercício de autoridade no âmbito do trabalho, ou seja, sua "vantagem de classe", realiza-se à custa de uma elevada penalidade salarial de gênero. A vantagem de escolaridade feminina permite entender os avanços obtidos pelas mulheres no acesso aos empregos de especialistas e de empregados qualificados. Apesar disso tudo, no entanto, ocorre uma elevada penalidade de gênero na categoria de especialistas, mostrando que esse contexto de classe deprecia o valor econômico da qualificação profissional e do conhecimento perito ostentados pelas mulheres. Merece destaque, por fim, o fato de que, para a categoria de gerente, a composição ocupacional de gênero gera uma redução ínfima da distância de gênero de renda, o que mostraria a inexistência de um efeito de discrepância de gênero na alocação entre os grupos ocupacionais de gerentes, conforme sua tipificação na classificação ocupacional da PNAD. Já o pequeno segmento altamente remunerado de profissionais autônomos, ao registrar uma distância de $23,68 \%$, parece mostrar, por contraposição, que a relação de emprego assalariado e de trabalho coletivo entre homens e mulheres, como ocorre entre os empregados especialistas, favorece o aumento da discrepância de gênero na remuneração, já que entre esses últimos ocorre uma diferença de $34,49 \%$.

As situações de classe ambíguas de empregados qualificados e supervisores mostram um quadro claramente divergente. O controle de ativos de qualificação, em um grau intermediário, pelos empregados qualificados, gera uma distância superior aos próprios empregados especialistas. Já entre os supervisores ocorre a segunda menor distância entre todas as treze categorias de classe e um claro contraste com a diferença muito mais elevada registrada entre os gerentes. 
Os trabalhadores revelam uma distância de gênero de renda (22,63\%) abaixo da distância média geral $(27,26 \%)$, mas ainda assim elevada, considerando que foi feito o controle estatístico da composição ocupacional de gênero da categoria. A idéia de que a condição de exploração de classe comum dos trabalhadores diminuiria o papel da opressão (não-classista) de gênero encontra aqui uma aplicação parcial e limitada, mostrando a existência de certa autonomia da divisão de gênero em relação ao condicionamento de classe. Em um sentido relativo ou comparativo, essa tese encontra uma expressão mais aceitável para a categoria de trabalhadores elementares, em que se conjugam trabalho assalariado e profunda destituição.

A situação encontrada entre os conta-próprias precários, categoria em que existe uma elevada diferença de gênero, merece uma ênfase especial, considerando seu grande peso relativo na estrutura social e o fato de o destino econômico de muitas mulheres depender desse contexto de classe. Na verdade, considerando a especificidade da estrutura de classe de países como o Brasil, a situação revelada nessa categoria mostra, de modo novo e inusitado, a importância de se considerarem os contextos de classe na análise da distância de gênero, visto que as mulheres não sofrem do mesmo modo e na mesma intensidade o ônus da penalidade de gênero. Os processos agudos de destituição de recursos, quando realizados fora da esfera comparativamente mais "padronizada" do trabalho assalariado proletarizado, parecem exacerbar significativamente a desigualdade de gênero em termos de capacidade geradora de renda. Esse contraste surge naturalmente da comparação da distância dessa categoria com os patamares encontrados entre os trabalhadores típicos, os trabalhadores elementares e os empregados domésticos.

Os empregados domésticos, por fim, revelam uma diferença de gênero $(23,36 \%)$ próxima da distância média $(27,26 \%)$, depois do controle estatístico da composição ocupacional de gênero. Esse resultado revela a força da desigualdade de tratamento de gênero, mesmo em uma categoria de renda média muito baixa, cujo efeito independe da segregação ocupacional de gênero existente no interior da categoria.

A comparação entre as divisões de gênero e de raça representa uma estratégia interessante para realçar as características da desigualdade de gênero e de suas interações com a desigualdade de classe no Brasil. Vejamos o comportamento da distância bruta de renda, entendido como 
as diferenças globais, não controladas, entre as rendas médias das categorias. Essa diferença bruta de gênero de renda, com o controle apenas das horas trabalhadas, mostra-se muito menos pronunciada que a distância bruta de raça ( $32 \%$ contra $75 \%)$. A ordem de classe e a segregação ocupacional atuam como relevantes fatores mediadores na produção da desigualdade de gênero, explicando quase $40 \%$ dessa desigualdade, como mostra a redução da distância não explicada ocorrida na passagem do modelo 7 para o modelo 9. A maior parte da diferença de gênero, porém, não se exerce através de mecanismos mediadores. Grande parte da distância de raça de renda decorre das desigualdades de acesso, em que entram naturalmente os componentes de discriminação incidentes nos processos de alocação. Já as mulheres, particularmente as brancas, possuem vantagens de acesso às credenciais educacionais.

As divisões de gênero revelam uma diferença controlada significativamente maior em comparação com as divisões de raça. A vantagem líquida de renda (controlada a desigualdade de acesso) dos homens sobre as mulheres em circunstâncias sociais semelhantes, de 35,16\%, mostrada na Tabela 6 , suplanta em muito a vantagem líquida de raça dos brancos sobre os não-brancos, de apenas $12,86 \%$, usando fatores de controle equivalentes (Figueiredo Santos, 2005b; 2006a). Os processos de seletividade social anteriores, muito mais fortes no caso de raça, determinam naturalmente a alocação das pessoas às circunstâncias. Ao serem controlados os resultados das desigualdades de gênero no acesso às várias circunstâncias ou recursos valiosos, a fim de isolar os efeitos diretos (não mediados) de gênero, independentes das associações parciais com outras variáveis, os dados obtidos mostram um elevado impacto da "desigualdade de tratamento" de gênero na renda das pessoas situadas nas mesmas circunstâncias sociais.

Embora as mulheres estejam inseridas de modo significativo particularmente em posições que controlam ativos de qualificação e exercem autoridade, ainda assim elas estão mais concentradas em posições de classe que oferecem menores recompensas, cujo agregado possui uma densidade bem maior na estrutura social, o que mostra a persistência de desvantagens de acesso. A condição de classe exerce um importante efeito moderador sobre a desigualdade de gênero de renda, particularmente entre os capitalistas, os gerentes e os detentores de ativos de qualificação, no sentido de sua acentuação, e entre os trabalhadores elementares, no sentido de sua atenuação. Esse efeito condicional, po- 
rém, é menos pronunciado e mais irregular quando comparado às interações entre classe e raça. Os condicionamentos de classe acentuam as distâncias de gênero de renda em pólos extremos da estrutura de classe, como capitalistas e autônomos precários, o que realça de modo diferenciado a importância dos efeitos contextuais e instiga a reflexão teórica sobre os mecanismos que geram essas conseqüências. O gênero se revela uma divisão social mais autônoma em relação à classe social quando essa divisão é confrontada com a divisão de raça. Existe no Brasil uma elevada desigualdade de tratamento de gênero, que parece suplantar a desigualdade de acesso a contextos e a recursos valiosos, e representa um ônus comum compartilhado pela mulher como uma decorrência direta do poder causal do atributo de gênero.

(Recebido para publicação em dezembro de 2006)

(Versão definitiva em março de 2008) 


\section{NOTAS}

1. Esse programa de investigação foi iniciado em 2004, quando, com o suporte de uma bolsa de pós-doutorado da Coordenação de Aperfeiçoamento de Pessoal de Nível Superior - Capes, estive como Honorary Fellow do Departamento de Sociologia da Universidade de Wisconsin-Madison, beneficiando-me da colaboração acadêmica do professor Erik Olin Wright. Foi elaborada, no período, uma nova classificação socioeconômica para o Brasil, operacionalizada para os microdados da Pesquisa Nacional por Amostra de Domicílios - PNAD. A validação de constructo dessa classificação explorou o condicionamento exercido pela esfera da desigualdade de classe sobre a desigualdade de raça no Brasil (ver Figueiredo Santos, 2005a; 2005b; 2006a; 2006b).

2. O modelo linear piecewise é um caso especial de um conjunto muito maior de modelos ou relações denominadas funções spline. Essas funções possuem partes distintas, mas o traçado representando o conjunto dos segmentos, ou potenciais quebras estruturais, é uma função contínua, e não necessariamente uma linha reta (Pindyck e Rubinfeld, 1998:136).

3. $47,9 \%$ dos supervisores estão na indústria de transformação, contra apenas $16,3 \%$ dos gerentes, $15,8 \%$ dos empregados qualificados e 10,5\% dos empregados especialistas.

4. A especificação Log-Gamma do Modelo Linear Generalizado, usada neste estudo, pode produzir um coeficiente estimado menor da distância de renda, em comparação à especificação linear - embora não exista um padrão sistemático nessa diferença - e à especificação Log-Poisson, devido ao fato de o modelo Log-Gamma realizar uma correção mais forte de heterocedasticidade (Petersen, 2006). Estimativas feitas por mim com uma especificação Log-Normal do Modelo Linear Generalizado mostraram distâncias de renda mais elevadas a favor do homem.

5. O coeficiente estimado é maior nas duas primeiras faixas compreendidas, respectivamente, entre 1 e 29 horas e entre 30 e 39 horas trabalhadas, em que as mulheres estão mais concentradas ( $45,5 \%$ de mulheres contra $21,36 \%$ de homens). A taxa de rendimento hora é menor na faixa de 40 a 49 horas trabalhadas, em que os homens estão mais concentrados (56,7\% de homens contra $42,8 \%$ de mulheres). Na última faixa, de 50 ou mais horas, em que existem mais homens (21,9\% de homens contra $11,7 \%$ de mulheres), o coeficiente fica em um patamar próximo ao da primeira faixa, de 1 a 29 horas, em que existem mais mulheres (31,7\% de mulheres contra $12,3 \%$ de homens). Além disso, um Modelo Linear Generalizado, não mostrado aqui, com a introdução do termo interativo entre gênero e log das horas trabalhadas, constata que as mulheres possuem uma vantagem geral no efeito das horas trabalhadas.

6. No estudo em questão, ao ser mudada a especificação, a penalidade de ser mulher passa de $-4,6 \%$ para $-7,6 \%$ entre os profissionais assalariados e altera-se de $-1,8 \%$ para $-13,0 \%$ entre os médicos. Mesmo entre categorias ocupacionais mais homogêneas, como profissionais e médicos, são bastante sérias as implicações das diferenças de especificação. O estudo do conjunto da estrutura social em um contexto de elevada desigualdade de renda, como o existente no Brasil, implica maior variabilidade e heterogeneidade de renda de gênero dentro das categorias. As diferenças entre as estimativas em função das especificações dos modelos são o resultado das diferenças na distribuição de homens e mulheres entre as horas trabalhadas e das diferenças nos 
coeficientes estimados das splines do log das faixas de horas trabalhadas. Ao constranger implicitamente em 1 o coeficiente do log das horas trabalhadas, o modelo de rendimento hora infla artificialmente o retorno das horas nas faixas de mais horas trabalhadas. Visto que os homens estão mais concentrados em tais regiões, em comparação com as mulheres, isso faz com que uma parte maior do nível de rendimento maior do homem seja creditado às horas trabalhadas em virtude desse erro de especificação, de modo que o diferencial não explicado de rendimento entre homem e mulher fique artificialmente menor (Morgan e Arthur, 2005:399-400). Esse resultado divergente ocorre em estimativas com diferentes variáveis de controle, como pode ser visto nos vários modelos que constam da Tabela 1-A do Anexo Estatístico.

7. O presente estudo abarca todas as pessoas que possuem um vínculo direto com a ordem de classe, ou seja, que possuem uma posição de classe assinalada. Apesar da variável classe não constar do modelo de regressão 3, podemos considerar a questão da maior inserção direta das mulheres brancas na ordem de classe. No artigo "A Interação Estrutural entre a Desigualdade de Raça e de Gênero no Brasil", ainda inédito, desdobro este estudo e analiso as variações raciais da distância de gênero de renda em virtude dos efeitos interativos entre as duas divisões sociais.

8. Menos de 8 anos representa sem educação fundamental completa; 8 a 10 anos equivale à posse de educação fundamental completa até o ensino médio incompleto; 11 a 14 anos representa ensino médio completo até curso superior incompleto; já 15 anos ou mais equivale à posse de curso superior completo. Em um Modelo Linear Generalizado semelhante, com a educação introduzida como variável contínua, a diferença de gênero estimada fica em $54,67 \%$.

9. Caberia considerar também a hipótese de que o "valor econômico" da educação pode variar conforme o gênero das pessoas, de modo que os homens poderiam, por exemplo, obter mais renda por nível de escolaridade, apesar de terem menos escolaridade, ao passo que as mulheres precisariam de mais escolaridade para obter avanços na renda. Esse ponto foi aprofundado no artigo “Discrepâncias de Gênero no Valor Econômico da Educação", ainda inédito.

10. Entre as pessoas com uma posição de classe assinalada, renda positiva e informação válida para todas as variáveis do estudo, que compõem a amostra da presente pesquisa, as mulheres alcançam uma média de 8,68 anos de estudo completos contra 7,13 anos dos homens. A média de escolaridade das mulheres supera a dos homens em quase todas as categorias de classe, exceto na dos conta-próprias agrícolas.

11. Os homens inseridos diretamente na ordem de classe em 2005 possuem em média 23,6 anos de trabalho contra 20,6 anos das mulheres; de modo semelhante, possuem em média 7,8 anos no trabalho atual contra 5,9 anos das mulheres.

12. O setor público engloba $11,89 \%$ das posições em 2005 , mas $17,39 \%$ das mulheres estão nele, contra apenas $8,24 \%$ dos homens. A renda média do setor público supera em $19,22 \%$ a do setor privado, segundo estimativa baseada no modelo 8 . Conforme o mesmo modelo, os setores econômicos que possuem maior renda média em 2005 são, na ordem, serviços produtivos, serviços de distribuição, indústria de transformação, serviços sociais, indústria extrativa e serviços pessoais (categoria de referência omitida). 


\section{REFERÊNCIAS BIBLIOGRÁFICAS}

ABBOTT, Pamela. (2000), "Gender", in G. Payne (ed.), Social Divisions. New York, St. Martin's Press, pp. 55-90.

ALBELDA, Randy, DRAGO, Robert W. e SHULMAN, Steven. (2001), Unlevel Playing Fields: Understanding Wage Inequality and Discrimination. Cambridge, Economic Affairs Bureau.

BIRKELUND, Gunn Elisabeth. (1992), "Stratification and Segregation". Acta Sociologica, vol. 35, no 1, pp. 47-62.

BLANK, Rebecca M., DABADY, Marilyn e CITRO, Constance F. (eds.). (2004), Measuring Racial Discrimination: Panel on Methods for Assessing Discrimination. Washington, National Academies Press.

BLAU, Francine D., FERBER, Marianne A. e WINKLER, Anne E. (1998), The Economics of Women, Men, and Work (3a ed.). Upper Saddle River, Prentice Hall.

BRADLEY, Harriet. (1996), Fractured Identities: Changing Patterns of Inequality. Cambridge, Polity Press.

BRAMBOR, Thomas, CLARK, William Roberts e GOLDER, Matt. (2006), “Understanding Interaction Models: Improving Empirical Analysis". Political Analysis, vol. 14, no 3, pp. 63-82.

BRUSCHINI, Cristina. (2000), “Gênero e Trabalho no Brasil: Novas Conquistas ou Persistência da Discriminação?", in M. I. B. da Rocha (org.), Trabalho e Gênero: Mudanças, Permanências e Desafios. São Paulo, Editora 34.

CHARLES, Maria. (2003), “Deciphering Sex Segregation: Vertical and Horizontal Inequalities in Ten National Labor Markets". Acta Sociologica, vol. 46, no 4, pp. 267-287.

e GRUSKY, David B. (2004), Occupational Ghettos: The Worldwide Segregation of Women and Men. Stanford, Stanford University Press.

COHEN, Jacob et alii. (2003), Applied Multiple Regression/Correlation Analysis for the Behavioral Sciences (3a ed.). Mahwah, Lawrence Erlbaum.

DE VAUS, David. (2002), Analyzing Social Science Data. 50 Key Problems in Data Analysis. London, Sage.

DUNCAN, Kevin C. (1996), "Gender Differences in the Effect of Education on the Slope of Experience-Earnings Profiles: National Longitudinal Survey of Youth, 1979-1988". American Journal of Economics and Sociology, vol. 55, no 4, pp. 457-471.

DUNTEMAN, George H. e HO, Moon-Ho R. (2006), An Introduction to Generalized Linear Models. Thousand Oaks, CA, Sage (Sage University Paper Series on Quantitative Applications in the Social Sciences, no 07-145).

FIGUEIREDO SANTOS, José Alcides. (2002), Estrutura de Posições de Classe no Brasil: Mapeamento, Mudanças e Efeitos na Renda. Belo Horizonte/Rio de Janeiro, Ed. UFMG/Iuperj.

(2005a), “Uma Classificação Socioeconômica para o Brasil”. Revista Brasileira de Ciências Sociais, vol. 20, no 58, pp. 27-45. 
. (2005b), “Efeitos de Classe na Desigualdade Racial no Brasil”. DADOS, vol. 48, no 1, pp. 21-65.

(2006a), "Class Effects on Racial Inequality in Brazil". DADOS, vol. 2 (Special English Edition). Disponível em http:/ / socialsciences.scielo.org.

. (2006b), "A Socioeconomic Classification for Brazil". Revista Brasileira de Ciências Sociais, vol. 2 (Special English Edition). Disponível em http://socialsciences.scielo.org.

GOODMAN, Leo A. (2006), A New Way to View the Magnitude of the Difference Between the Arithmetic Mean and the Geometric Mean, and the Difference Between the Slopes when a Continuous Dependent Variable is Expressed in Raw Form Versus Logged Form. Working Paper, Departamento de Sociologia e Departamento de Estatística, University of California, Berkeley.

GORNICK, Janet C. (1999), "Gender Equality in the Labour Market", in D. Sainsbury (ed.), Gender and Welfare State Regimes. Oxford, Oxford University Press.

GUNDERSON, Morley. (1989), "Male-Female Wage Differentials and Policy Responses". Journal of Economic Literature, vol. 27, no 1, pp. 46-72.

HARDIN, James W. e HILBE, Joseph M. (2007), Generalized Linear Models and Extensions (2a ed.). College Station, Stata Press.

HARDY, Melissa A. (1993), Regression with Dummy Variables. Newbury Park, CA, Sage (Sage University Paper Series on Quantitative Applications in the Social Sciences, no 07-093).

HEILBORN, Maria Luiza e SORJ, Bila. (1999), “Estudos de Gênero no Brasil”, in S. Miceli (org.), O que Ler na Ciência Social Brasileira. São Paulo/Brasília, Sumaré/Anpocs/Capes, vol. 2.

HOYLE, Rick H. e ROBINSON, Jorgianne Civey. (2004), “Mediated and Moderated Effects in Social Psychological Research: Measurement, Design, and Analysis Issues", in C. Sansone, C. C. Morf e A. T. Panter (eds.), The Sage Handbook of Methods in Social Psychology. Thousand Oaks, Sage.

IBGE - Instituto Brasileiro de Geografia e Estatística. (2006), Pesquisa Nacional por Amostra de Domicílios: 2005. Microdados. Rio de Janeiro, IBGE.

JACCARD, James e TURRISI, Robert. (2003), Interaction Effects in Multiple Regression (2a ed.). Thousand Oaks, CA, Sage (Sage University Paper Series on Quantitative Applications in the Social Sciences, no 07-072).

JACOBSEN, Joyce P. (1997), The Economics of Gender. Malden, Blackwell.

KAM, Cindy e FRANZESE JR., Robert J. (2007), Modeling and Interpreting Interactive Hypotheses in Regression Analysis: A Refresher and Some Practical Advice. Ann Arbor, University of Michigan Press.

MARINI, Margaret M. e FAN, Pi-Ling. (2001), "The Gender Gap in Earnings at Career Entry", in D. B. Grusky (ed.), Social Stratification: Class, Race, and Gender in Sociological Perspective (2⿺ ed.). Boulder, Westview Press.

MARTIN, Patricia Yancey. (2004), “Gender as Social Institution”. Social Forces, vol. 84, no 4, pp. 1249-1273. 
MCCALL, Leslie. (2001), Complex Inequality: Gender, Class, and Race in the New Economy. New York, Routledge.

MORGAN, Laurie A. e ARTHUR, Michelle M. (2005), “Methodological Considerations in Estimating the Gender Pay Gap for Employed Professionals". Sociological Methods E Research, vol. 33, no 3, pp. 383-403.

MORRIS, Martina e WESTERN, Bruce. (1999), "Inequality in Earnings at the Close of the Twentieth Century". Annual Review of Sociology, vol. 25, pp. 623-657.

MUKHERJEE, Chadan, WHITE, Howard e WUYTS, Marc. (1998), Econometrics and Data Analysis for Developing Countries. London, Routledge.

OLIVEIRA, Ana Maria Hermeto Camilo de. (2003), "A Segregação Ocupacional por Gênero e seus Efeitos sobre os Salários no Brasil”, in S. Wajnman e A. F. Machado (orgs.), Mercado de Trabalho: Uma Análise a partir das Pesquisas Domiciliares no Brasil. Belo Horizonte, Ed. UFMG.

PEDHAZUR, Elazar J. (1982), Multiple Regression in Behavioral Research. Explanation and Prediction (2a ed.). Fort Worth, Harcourt Brace Jovanovich.

PETERSEN, Trond. (2006), “Functional Form for Continuous Dependent Variables: Raw Versus Logged Form". Working Paper, Departamento de Sociologia, University of California, Berkeley.

e MORGAN, Laurie A. (1995), "Separate and Unequal: Occupation-Establishment Sex Segregation and the Gender Wage Gap". American Journal of Sociology, vol. 102, no 2, pp. 329-365.

PINDYCK, Robert S. e RUBINFELD, Daniel L. (1998), Econometric Models and Economic Forecasts (4a ed.). Boston, Irwin/McGraw-Hill.

RESKIN, Barbara e PADAVIC, Irene. (1994), Women and Men at Work. Thousand Oaks, Pine Forge Press.

RIDGEWAY, Cecilia L. e SMITH-LOVIN, Lynn. (1999), “The Gender System and Interaction". Annual Review of Sociology, vol. 25, pp. 191-216.

RIMA, Ingrid H. (1996), Labor Markets in a Global Economy: An Introduction. Armonk, M. E. Sharpe.

ROSENBERG, Morris. (1976), A Lógica da Análise do Levantamento de Dados. São Paulo, Cultrix/USP.

SOKOLOFF, Natalie J. (1992), Black Women and White Women in the Professions. New York, Routledge.

STATA. (2005), Stata Base Reference Manual. College Station, Stata Press (vols. 1-3).

WEEDEN, Kim A. (2004), "Profiles of Change: Sex Segregation in the United States, 1910-2000", in M. Charles e D. B. Grusky, Occupational Ghettos: The Worldwide Segregation of Women and Men. Stanford, Stanford University Press.

WHARTON, Amy S. (2004), The Sociology of Gender: An Introduction to Theory and Research. Oxford, Blackwell.

WRIGHT, Erik Olin. (1994), Interrogating Inequality: Essays on Class Analysis, Socialism and Marxism. London, Verso. 
. (1997), Class Counts: Comparative Studies in Class Analysis. Cambridge, Cambridge University Press.

. (2001), "A Conceptual Menu for Studying the Interconnections of Class and Gender", in J. Baxter e M. Western (eds.), Reconfigurations of Class and Gender. Stanford, Stanford University Press.

. (2004), "Social Class", in G. Ritzer (ed.), Encyclopedia of Social Theory. Thousand Oaks, Sage.

(2005), "Foundations of a Neo-Marxist Class Analysis", in E. O. Wright (ed.), Approaches to Class Analysis. Cambridge, Cambridge University Press. Disponível em http://www.ssc.wisc.edu/ wright.

WU, Huei-Hsia. (2002), Wages and Employment Differences between Married Asian American and Non-Hispanic White Women. Tese de doutorado, The University of Texas at Austin, Texas. Disponível em http://repositories.tdl.org/handle/ $2152 / 658$. 


\begin{tabular}{|c|c|}
\hline \multicolumn{2}{|c|}{$\begin{array}{c}\text { Quadro 1 } \\
\text { Uma Classificação Socioeconômica para o Brasil: } \\
\text { Categorias Empíricas e Critérios Operacionais }\end{array}$} \\
\hline Categorias & Critérios Operacionais \\
\hline Capitalista e fazendeiro & $\begin{array}{l}\text { Posição na ocupação de empregador; empregador } \\
\text { não-agrícola com } 11 \text { ou mais empregados; empregador } \\
\text { agrícola com } 11 \text { ou mais empregados permanentes; em- } \\
\text { pregador agrícola que emprega simultaneamente } 6 \text { ou } \\
\text { mais empregados permanentes e } 11 \text { ou mais empregados } \\
\text { temporários; empregador agrícola com } 1.000 \text { hectares ou } \\
\text { mais de terra, independentemente do número de empre- } \\
\text { gados. }\end{array}$ \\
\hline Pequeno empregador & $\begin{array}{l}\text { Posição na ocupação de empregador; empregador } \\
\text { não-agrícola que ocupa de } 1 \text { a } 10 \text { empregados; emprega- } \\
\text { dor agrícola que ocupa de } 1 \text { a } 10 \text { empregados permanen- } \\
\text { tes, desde que não empregue simultaneamente de } 6 \text { a } 10 \\
\text { empregados permanentes e } 11 \text { ou mais empregados tem- } \\
\text { porários. }\end{array}$ \\
\hline Conta-própria não-agrícola & $\begin{array}{l}\text { Posição na ocupação de conta-própria com atividade de } \\
\text { natureza não-agrícola, cujo empreendimento ou titular } \\
\text { possui uma ou mais das seguintes condições: estabeleci- } \\
\text { mento (loja, oficina, fábrica, escritório, banca de jornal ou } \\
\text { quiosque), veículo automotor (táxi, caminhão, van etc.) } \\
\text { usado para trabalhar ou ocupação qualificada no emprego } \\
\text { principal. }\end{array}$ \\
\hline Conta-própria agrícola & $\begin{array}{l}\text { Posição na ocupação de conta-própria com atividade em } \\
\text { empreendimento do ramo que compreende agricultura, } \\
\text { silvicultura, pecuária, extração vegetal, pesca e piscicul- } \\
\text { tura. }\end{array}$ \\
\hline Especialista autônomo & $\begin{array}{l}\text { Posição na ocupação de conta-própria ou empregador; es- } \\
\text { pecialista de acordo com o grupo ocupacional, com até } 5 \\
\text { empregados ou sem empregados, com ou sem estabeleci- } \\
\text { mento (loja, oficina, fábrica, escritório). }\end{array}$ \\
\hline Gerente & $\begin{array}{l}\text { Posição na ocupação de empregado; gerente de acordo } \\
\text { com o grupo ocupacional, abarcando os diretores de em- } \\
\text { presas, dirigentes da administração pública, administra- } \\
\text { dores em organizações de interesse público (sem fins lu- } \\
\text { crativos etc.) e gerentes de produção, de operações e de } \\
\text { áreas de apoio. }\end{array}$ \\
\hline
\end{tabular}

(continua) 


\section{Quadro 1}

Uma Classificação Socioeconômica para o Brasil:

Categorias Empíricas e Critérios Operacionais

(continuação)

\begin{tabular}{|c|c|}
\hline Categorias & Critérios Operacionais \\
\hline Empregado especialista & $\begin{array}{l}\text { Posição na ocupação de empregado; especialista de acor- } \\
\text { do com o grupo ocupacional, incluindo as profissões cre- } \\
\text { denciadas, as profissões de menor poder profissional e os } \\
\text { professores do ensino médio e profissional com formação } \\
\text { superior. }\end{array}$ \\
\hline Empregado qualificado & $\begin{array}{l}\text { Posição na ocupação de empregado; empregado qualifica- } \\
\text { do de acordo com o grupo ocupacional, abarcando os téc- } \\
\text { nicos de nível médio nas diversas áreas, professores de ní- } \\
\text { vel médio ou com formação superior no ensino infantil, } \\
\text { fundamental e profissional, professores de educação física } \\
\text { e de educação especial. }\end{array}$ \\
\hline Supervisor & $\begin{array}{l}\text { Posição na ocupação de empregado; supervisor, chefe, } \\
\text { mestre ou contramestre de acordo com o grupo ocupacio- } \\
\text { nal. }\end{array}$ \\
\hline Trabalhador típico & $\begin{array}{l}\text { Posição na ocupação de empregado; trabalhador em repa- } \\
\text { ração e manutenção mecânica, ferramenteiro e operador } \\
\text { de centro de usinagem; trabalhador de semi-rotina na ope- } \\
\text { ração de instalações químicas, petroquímicas e de geração } \\
\text { e distribuição de energia; trabalhador de semi-rotina em } \\
\text { serviços administrativos, comércio e vendas; trabalhador } \\
\text { de rotina na operação de máquinas e montagem na indús- } \\
\text { tria; trabalhador de rotina em serviços administrativos, } \\
\text { comércio e vendas. }\end{array}$ \\
\hline Trabalhador elementar & $\begin{array}{l}\text { Posição na ocupação de empregado; trabalhador com tare- } \\
\text { fas de trabalho bastante elementares na indústria e nos } \\
\text { serviços, como ajudantes de obras, trabalhadores elemen- } \\
\text { tares na manutenção de vias públicas, faxineiros, lixeiros e } \\
\text { carregadores de carga; trabalhadores manuais agrícolas, } \\
\text { garimpeiros e salineiros, excluindo os trabalhadores na } \\
\text { mecanização agrícola, florestal e drenagem. }\end{array}$ \\
\hline Conta-própria precário & $\begin{array}{l}\text { Posição na ocupação de conta-própria e empreendimento } \\
\text { ou titular sem a posse de nenhuma das seguintes condi- } \\
\text { ções: estabelecimento (loja, oficina, fábrica, escritório, } \\
\text { banca de jornal ou quiosque), veículo automotor (táxi, ca- } \\
\text { minhão, van etc.) usado para o trabalho ou ocupação qua- } \\
\text { lificada no emprego principal; posição na ocupação de tra- } \\
\text { balhador na produção do próprio consumo; posição na } \\
\text { ocupação de trabalhador na construção para o próprio } \\
\text { uso. }\end{array}$ \\
\hline Empregado doméstico & $\begin{array}{l}\text { Posição na ocupação de trabalhador doméstico, com ou } \\
\text { sem carteira de trabalho assinada. }\end{array}$ \\
\hline
\end{tabular}

Fonte: Figueiredo Santos (2005b). 


\section{Quadro 2}

Relação e Descrição das Variáveis Utilizadas no Estudo

\begin{tabular}{|c|c|}
\hline Variáveis & Descriçãa \\
\hline Renda & $\begin{array}{l}\text { Variável dependente contínua. Rendimento } \\
\text { mensal do trabalho principal; considera-se } \\
\text { rendimento mensal do trabalho a remunera- } \\
\text { ção bruta mensal para empregados e trabalha- } \\
\text { dores domésticos e a retirada mensal para con- } \\
\text { ta-própria e empregadores; no caso de renda } \\
\text { variável, valor médio mensal. }\end{array}$ \\
\hline Horas de trabalho & $\begin{array}{l}\text { Linear spline do equivalente em log das faixas } \\
\text { de horas de trabalho estipuladas: } 1 \text { a } 29 \text { horas, } \\
30 \text { a } 39 \text { horas, } 40 \text { a } 49 \text { horas e } 50 \text { horas ou mais } \\
\text { de trabalho semanal. }\end{array}$ \\
\hline Classe & $\begin{array}{l}\text { Variáveis binárias. Capitalista, pequeno em- } \\
\text { pregador, auto-empregado especialista, con- } \\
\text { ta-própria não-agrícola, conta-própria agríco- } \\
\text { la, empregado especialista, gerente, emprega- } \\
\text { do qualificado, supervisor, trabalhador, con- } \\
\text { ta-própria precário, empregado doméstico, } \\
\text { como categorias designadas, código } 1 \text {; traba- } \\
\text { lhador elementar, como categoria de referên- } \\
\text { cia, código } 0 .\end{array}$ \\
\hline Gênero & $\begin{array}{l}\text { Variável binária. Masculino, como categoria } \\
\text { designada, código } 1 \text {; feminino, como catego- } \\
\text { ria de referência, código } 0 .\end{array}$ \\
\hline Composição de gênero das ocupações & $\begin{array}{l}\text { Variável contínua. Proporção de mulheres nos } \\
\text { grupos ocupacionais estimada usando o códi- } \\
\text { go ocupacional de quatro dígitos da Classifi- } \\
\text { cação Brasileira de Ocupações - CBO Domici- } \\
\text { liar. }\end{array}$ \\
\hline Educação & $\begin{array}{l}\text { Variáveis binárias. Grupos de } 8 \text { a } 10 \text { anos, de } 11 \\
\text { a } 14 \text { anos, } 15 \text { anos ou mais de escolaridade } \\
\text { completa, como categorias designadas; grupo } \\
\text { com menos de } 8 \text { anos, como categoria de refe- } \\
\text { rência. }\end{array}$ \\
\hline Anos de trabalho & $\begin{array}{l}\text { Variável contínua, idade menos a idade em } \\
\text { que começou a trabalhar. }\end{array}$ \\
\hline Anos de trabalho² & $\begin{array}{l}\text { Variável contínua, quadrado dos anos de tra- } \\
\text { balho. }\end{array}$ \\
\hline Anos no trabalho atual & $\begin{array}{l}\text { Variável contínua, número de anos no traba- } \\
\text { lho principal atual, com valores a partir de } 0 \\
\text { (menos de } 1 \text { ano). }\end{array}$ \\
\hline
\end{tabular}

(continua) 
José Alcides Figueiredo Santos

Quadro 2

Relação e Descrição das Variáveis Utilizadas no Estudo

\begin{tabular}{|c|c|}
\hline Variáveis & Descrição \\
\hline Anos no trabalho atual ${ }^{2}$ & $\begin{array}{l}\text { Variável contínua, quadrado dos anos no tra- } \\
\text { balho principal atual. }\end{array}$ \\
\hline Região & $\begin{array}{l}\text { Variáveis binárias. Regiões Sudeste, Sul, Cen- } \\
\text { tro-Oeste, como categorias designadas, códi- } \\
\text { go } 1 \text {; Nordeste como categoria de referência, } \\
\text { código } 0 .\end{array}$ \\
\hline Residência & $\begin{array}{l}\text { Variável binária. Residência urbana como ca- } \\
\text { tegoria designada, código } 1 \text {; residência rural } \\
\text { como categoria de referência, código } 0 \text {. }\end{array}$ \\
\hline Migração & $\begin{array}{l}\text { Variável binária. Pessoa nascida em outro mu- } \\
\text { nicípio que não o município de residência, } \\
\text { como categoria designada, código } 1 \text {; pessoa } \\
\text { nascida no município de residência, como ca- } \\
\text { tegoria de referência, código } 0 \text {. }\end{array}$ \\
\hline Setor público/privado & $\begin{array}{l}\text { Variável binária. Setor público federal, estadu- } \\
\text { al ou municipal, abrangendo, além da admi- } \\
\text { nistração direta, suas fundações, autarquias e } \\
\text { empresas públicas e de economia mista, como } \\
\text { categoria designada, código } 1 \text {; setor privado, } \\
\text { como categoria de referência, código } 0 \text {. }\end{array}$ \\
\hline Setores econômicos & $\begin{array}{l}\text { Variáveis binárias. Indústria de transforma- } \\
\text { ção, indústria extrativa, serviços produtivos, } \\
\text { serviços de distribuição e serviços sociais, } \\
\text { como categorias designadas, código 1; servi- } \\
\text { ços pessoais, como categoria de referência, có- } \\
\text { digo } 0 \text {. }\end{array}$ \\
\hline Raça & $\begin{array}{l}\text { Variáveis binárias. Branco, preto, amarelo e in- } \\
\text { dígena, como categorias designadas, código 1; } \\
\text { pardo, como categoria de referência, código } 0 .\end{array}$ \\
\hline Classe * gênero & $\begin{array}{l}\text { Variáveis binárias. Termos multiplicativos (in- } \\
\text { terativos) entre as variáveis binárias de classe } \\
\text { e de gênero. }\end{array}$ \\
\hline
\end{tabular}




\section{ANEXO ESTATÍSTICO}

Tabela 1-A

Coeficientes Estimados da Vantagem Relativa de Renda, em Favor do Homem, em Relação à Mulher, e Variáveis de Controle, de Acordo com Diferentes Modelos Lineares Generalizados

\begin{tabular}{|c|c|c|c|c|c|c|c|c|c|}
\hline Variáveis & Modelo 1 & Modelo 2 & Modelo 3 & Modelo 4 & Modelo 5 & Modelo 6 & Modelo 7 & Modelo 8 & Modelo 9 \\
\hline (Constante) & $\begin{array}{c}6,4149 \\
(0,0070)\end{array}$ & $\begin{array}{c}4,9536 \\
(0,0439)\end{array}$ & $\begin{array}{c}4,6465 \\
(0,0401)\end{array}$ & $\begin{array}{c}4,2650 \\
(0,0308)\end{array}$ & $\begin{array}{c}3,7546 \\
(0,0278)\end{array}$ & $\begin{array}{c}3,2990 \\
(0,0286)\end{array}$ & $\begin{array}{c}3,3408 \\
(0,0297)\end{array}$ & $\begin{array}{c}3,3859 \\
(0,0244)\end{array}$ & $\begin{array}{c}3,5262 \\
(0,0252)\end{array}$ \\
\hline Homem & $\begin{array}{r}0,3293 \\
(0,0090) \\
\end{array}$ & $\begin{array}{c}0,2764 \\
(0,0091)\end{array}$ & $\begin{array}{c}0,2887 \\
(0,0083)\end{array}$ & $\begin{array}{c}0,4222 \\
(0,0062)\end{array}$ & $\begin{array}{c}0,3606 \\
(0,0055)\end{array}$ & $\begin{array}{c}0,3820 \\
(0,0054)\end{array}$ & $\begin{array}{c}0,3698 \\
(0,0059)\end{array}$ & $\begin{array}{c}0,3012 \\
(0,0047)\end{array}$ & $\begin{array}{c}0,2410 \\
(0,0054)\end{array}$ \\
\hline Lghs 1 a 29 & & $\begin{array}{c}0,3800 \\
(0,0144)\end{array}$ & $\begin{array}{c}0,3723 \\
(0,0131)\end{array}$ & $\begin{array}{r}0,3134 \\
(0,0100)\end{array}$ & $\begin{array}{c}0,2874 \\
(0,0089)\end{array}$ & $\begin{array}{c}0,2939 \\
(0,0089)\end{array}$ & $\begin{array}{c}0,2789 \\
(0,0091)\end{array}$ & $\begin{array}{c}0,2785 \\
(0,0069)\end{array}$ & $\begin{array}{c}0,2800 \\
(0,0069)\end{array}$ \\
\hline Lghs 30 a 39 & & $\begin{array}{r}1,3235 \\
(0,0491)\end{array}$ & $\begin{array}{c}1,2207 \\
(0,0447)\end{array}$ & $\begin{array}{c}1,0421 \\
(0,0338)\end{array}$ & $\begin{array}{c}1,0609 \\
(0,0297)\end{array}$ & $\begin{array}{c}0,9070 \\
(0,0296)\end{array}$ & $\begin{array}{c}0,8967 \\
(0,0303)\end{array}$ & $\begin{array}{c}0,8932 \\
(0,0235)\end{array}$ & $\begin{array}{c}0,8760 \\
(0,0235)\end{array}$ \\
\hline Lghs 40 a 49 & & $\begin{array}{l}-1,3626 \\
(0,0606)\end{array}$ & $\begin{array}{l}-1,1994 \\
(0,0552)\end{array}$ & $\begin{array}{c}0,0535 \\
(0,0421)\end{array}$ & $\begin{array}{c}0,1552 \\
(0,0370)\end{array}$ & $\begin{array}{c}0,1908 \\
(0,0367)\end{array}$ & $\begin{array}{c}0,3242 \\
(0,0378)\end{array}$ & $\begin{array}{c}0,2003 \\
(0,0289)\end{array}$ & $\begin{array}{c}0,1879 \\
(0,0289)\end{array}$ \\
\hline Lghs 50 mais & & $\begin{array}{c}1,0866 \\
(0,0580)\end{array}$ & $\begin{array}{r}0,9802 \\
(0,0526)\end{array}$ & $\begin{array}{c}0,8462 \\
(0,0387)\end{array}$ & $\begin{array}{c}0,6162 \\
(0,0337)\end{array}$ & $\begin{array}{c}0,6301 \\
(0,0336)\end{array}$ & $\begin{array}{r}0,6288 \\
(0,0342)\end{array}$ & $\begin{array}{r}0,3083 \\
(0,0261)\end{array}$ & $\begin{array}{c}0,3075 \\
(0,0261)\end{array}$ \\
\hline Branco & & & $\begin{array}{c}0,5996 \\
(0,0082)\end{array}$ & $\begin{array}{c}0,3099 \\
(0,0062)\end{array}$ & $\begin{array}{c}0,2676 \\
(0,0055)\end{array}$ & $\begin{array}{c}0,1903 \\
(0,0059)\end{array}$ & $\begin{array}{c}0,1877 \\
(0,0060)\end{array}$ & $\begin{array}{c}0,1218 \\
(0,0046)\end{array}$ & $\begin{array}{c}0,1235 \\
(0,0045)\end{array}$ \\
\hline Preto & & & $\begin{array}{c}0,0077 \\
(0,0156)\end{array}$ & $\begin{array}{c}0,0212 \\
(0,0116)\end{array}$ & $\begin{array}{c}0,0114 \\
(0,0101) \\
\end{array}$ & $\begin{array}{l}-0,0059 \\
(0,0101) \\
\end{array}$ & $\begin{array}{r}-0,0028 \\
(0,0102) \\
\end{array}$ & $\begin{array}{c}0,0284 \\
(0,0078)\end{array}$ & $\begin{array}{c}0,0265 \\
(0,0078)\end{array}$ \\
\hline Amarelo & & & $\begin{array}{c}1,1504 \\
(0,0611)\end{array}$ & $\begin{array}{c}0,5365 \\
(0,0455)\end{array}$ & $\begin{array}{c}0,4544 \\
(0,0397)\end{array}$ & $\begin{array}{r}0,3359 \\
(0,0395)\end{array}$ & $\begin{array}{c}0,3486 \\
(0,0400)\end{array}$ & $\begin{array}{c}0,2013 \\
(0,0305)\end{array}$ & $\begin{array}{r}0,2025 \\
(0,0305)\end{array}$ \\
\hline
\end{tabular}


Tabela 1-A

Coeficientes Estimados da Vantagem Relativa de Renda, em Favor do Homem, em Relação à Mulher, e Variáveis de Controle, de Acordo com Diferentes Modelos Lineares Generalizados

(continuação)

\begin{tabular}{|c|c|c|c|c|c|c|c|c|c|}
\hline Variáveis & Modelo 1 & Modelo 2 & Modelo 3 & Modelo 4 & Modelo 5 & Modelo 6 & Modelo 7 & Modelo 8 & Modelo 9 \\
\hline Indígena & & & $\begin{array}{c}0,1683 \\
(0,0816) \\
\end{array}$ & $\begin{array}{c}0,0776 \\
(0,0606)\end{array}$ & $\begin{array}{c}0,0741 \\
(0,0529) \\
\end{array}$ & $\begin{array}{c}0,0131 \\
(0,0525)\end{array}$ & $\begin{array}{c}0,0205 \\
(0,0532) \\
\end{array}$ & $\begin{array}{c}0,0192 \\
(0,0406) \\
\end{array}$ & $\begin{array}{c}0,0150 \\
(0,0405)\end{array}$ \\
\hline Edu 8 a 10 & & & & $\begin{array}{r}0,2678 \\
(0,0084) \\
\end{array}$ & $\begin{array}{c}0,3790 \\
(0,0075) \\
\end{array}$ & $\begin{array}{c}0,3296 \\
(0,0075)\end{array}$ & $\begin{array}{c}0,2978 \\
(0,0077) \\
\end{array}$ & $\begin{array}{c}0,2031 \\
(0,0059) \\
\end{array}$ & $\begin{array}{r}0,2070 \\
(0,0059) \\
\end{array}$ \\
\hline Edu 11 a 14 & & & & $\begin{array}{c}0,7486 \\
(0,0071) \\
\end{array}$ & $\begin{array}{c}0,8310 \\
(0,0064) \\
\end{array}$ & $\begin{array}{c}0,7893 \\
(0,0065)\end{array}$ & $\begin{array}{c}0,7231 \\
(0,0069) \\
\end{array}$ & $\begin{array}{c}0,4865 \\
(0,0057) \\
\end{array}$ & $\begin{array}{c}0,4982 \\
(0,0057) \\
\end{array}$ \\
\hline Edu 15 & & & & $\begin{array}{r}1,7736 \\
(0,0112) \\
\end{array}$ & $\begin{array}{c}1,7546 \\
(0,0100) \\
\end{array}$ & $\begin{array}{c}1,699 \\
(0,0100)\end{array}$ & $\begin{array}{c}1,6078 \\
(0,0108) \\
\end{array}$ & $\begin{array}{r}1,0276 \\
(0,0099) \\
\end{array}$ & $\begin{array}{c}1,0447 \\
(0,0099) \\
\end{array}$ \\
\hline Anos de trabalho & & & & & $\begin{array}{c}0,0318 \\
(0,0006) \\
\end{array}$ & $\begin{array}{c}0,0289 \\
(0,0006)\end{array}$ & $\begin{array}{c}0,0283 \\
(0,0006) \\
\end{array}$ & $\begin{array}{c}0,0260 \\
(0,0004) \\
\end{array}$ & $\begin{array}{c}0,0255 \\
(0,0004) \\
\end{array}$ \\
\hline Anos de trabalho ${ }^{2}$ & & & & & $\begin{array}{c}-0,0004 \\
(0,00001) \\
\end{array}$ & $\begin{array}{c}-0,0003 \\
(0,00001)\end{array}$ & $\begin{array}{c}-0,0003 \\
(0,00001) \\
\end{array}$ & $\begin{array}{c}-0,0003 \\
(0,000008) \\
\end{array}$ & $\begin{array}{c}-0,0003 \\
(0,000008) \\
\end{array}$ \\
\hline Anos no atual emprego & & & & & $\begin{array}{c}0,0310 \\
(0,0007)\end{array}$ & $\begin{array}{c}0,0315 \\
(0,0007) \\
\end{array}$ & $\begin{array}{c}0,0300 \\
(0,0007) \\
\end{array}$ & $\begin{array}{c}0,0242 \\
(0,0005) \\
\end{array}$ & $\begin{array}{c}0,0241 \\
(0,0005) \\
\end{array}$ \\
\hline Anos no atual emprego ${ }^{2}$ & & & & & $\begin{array}{c}-0,0005 \\
(0,00001) \\
\end{array}$ & $\begin{array}{c}-0,0004 \\
(0,00001)\end{array}$ & $\begin{array}{c}-0,0004 \\
(0,00001) \\
\end{array}$ & $\begin{array}{c}-0,0003 \\
(0,00001) \\
\end{array}$ & $\begin{array}{c}-0,0003 \\
(0,00001) \\
\end{array}$ \\
\hline Norte & & & & & & $\begin{array}{c}0,2609 \\
(0,0087) \\
\end{array}$ & $\begin{array}{c}0,2568 \\
(0,0088) \\
\end{array}$ & $\begin{array}{c}0,2604 \\
(0,0067) \\
\end{array}$ & $\begin{array}{c}0,2595 \\
(0,0067) \\
\end{array}$ \\
\hline Centro-Oeste & & & & & & $\begin{array}{c}0,4077 \\
(0,0090)\end{array}$ & $\begin{array}{c}0,4072 \\
(0,0091)\end{array}$ & $\begin{array}{c}0,3942 \\
(0,0069)\end{array}$ & $\begin{array}{c}0,3933 \\
(0,0069)\end{array}$ \\
\hline
\end{tabular}


Tabela 1-A

Coeficientes Estimados da Vantagem Relativa de Renda, em Favor do Homem, em Relação à Mulher, e Variáveis de Controle, de Acordo com Diferentes Modelos Lineares Generalizados

(continuação)

\begin{tabular}{|c|c|c|c|c|c|c|c|c|c|}
\hline Variáveis & Modelo 1 & Modelo 2 & Modelo 3 & Modelo 4 & Modelo 5 & Modelo 6 & Modelo 7 & Modelo 8 & Modelo 9 \\
\hline Sul & & & & & & $\begin{array}{c}0,3323 \\
(0,0084)\end{array}$ & $\begin{array}{r}0,3356 \\
(0,0085)\end{array}$ & $\begin{array}{c}0,3518 \\
(0,0065)\end{array}$ & $\begin{array}{c}0,3498 \\
(0,0065)\end{array}$ \\
\hline Sudeste & & & & & & $\begin{array}{r}0,3159 \\
(0,0068)\end{array}$ & $\begin{array}{c}0,3214 \\
(0,0069)\end{array}$ & $\begin{array}{c}0,3395 \\
(0,0053)\end{array}$ & $\begin{array}{c}0,3389 \\
(0,0053)\end{array}$ \\
\hline Residência urbana & & & & & & $\begin{array}{c}0,2837 \\
(0,0078)\end{array}$ & $\begin{array}{c}0,1967 \\
(0,0091)\end{array}$ & $\begin{array}{c}0,1515 \\
(0,0071)\end{array}$ & $\begin{array}{c}0,1500 \\
(0,0071)\end{array}$ \\
\hline Migrante & & & & & & $\begin{array}{c}0,1178 \\
(0,0053)\end{array}$ & $\begin{array}{c}0,1199 \\
(0,0054)\end{array}$ & $\begin{array}{c}0,1028 \\
(0,0041)\end{array}$ & $\begin{array}{c}0,1021 \\
(0,0041)\end{array}$ \\
\hline Setor público & & & & & & & $\begin{array}{c}0,0997 \\
(0,0117)\end{array}$ & $\begin{array}{c}0,1757 \\
(0,0092)\end{array}$ & $\begin{array}{c}0,1679 \\
(0,0092)\end{array}$ \\
\hline Indústria extrativa & & & & & & & $\begin{array}{l}-0,0588 \\
(0,0117) \\
\end{array}$ & $\begin{array}{c}0,0279 \\
(0,0122)\end{array}$ & $\begin{array}{l}-0,0288 \\
(0,0125)\end{array}$ \\
\hline Indústria de transformação & & & & & & & $\begin{array}{r}0,1094 \\
(0,0090)\end{array}$ & $\begin{array}{c}0,0606 \\
(0,0085)\end{array}$ & $\begin{array}{c}0,0134 \\
(0,0088)\end{array}$ \\
\hline Serviços produtivos & & & & & & & $\begin{array}{c}0,2403 \\
(0,0117)\end{array}$ & $\begin{array}{c}0,1524 \\
(0,0103)\end{array}$ & $\begin{array}{r}0,1194 \\
(0,0104)\end{array}$ \\
\hline Serviços de distribuição & & & & & & & $\begin{array}{c}0,1790 \\
(0,0087)\end{array}$ & $\begin{array}{c}0,0887 \\
(0,0082)\end{array}$ & $\begin{array}{c}0,0515 \\
(0,0084)\end{array}$ \\
\hline Serviços sociais & & & & & & & $\begin{array}{c}0,1528 \\
(0,0123)\end{array}$ & $\begin{array}{c}0,0392 \\
(0,0109)\end{array}$ & $\begin{array}{r}0,0366 \\
(0,0109)\end{array}$ \\
\hline
\end{tabular}


Tabela 1-A

Coeficientes Estimados da Vantagem Relativa de Renda, em Favor do Homem, em Relação à Mulher, e Variáveis de Controle,

de Acordo com Diferentes Modelos Lineares Generalizados

(continuação)

\begin{tabular}{|c|c|c|c|c|c|c|c|c|c|}
\hline Variáveis & Modelo 1 & Modelo 2 & Modelo 3 & Modelo 4 & Modelo 5 & Modelo 6 & Modelo 7 & Modelo 8 & Modelo 9 \\
\hline \multirow[t]{2}{*}{ Capitalista } & & & & & & & & 1,8720 & 1,8712 \\
\hline & & & & & & & & $(0,0271)$ & $(0,0270)$ \\
\hline \multirow[t]{2}{*}{ Pequeno empregador } & & & & & & & & 1,1534 & 1,1531 \\
\hline & & & & & & & & $(0,0126)$ & $(0,0126)$ \\
\hline \multirow[t]{2}{*}{ Conta-própria não-agrícola } & & & & & & & & 0,5219 & 0,5291 \\
\hline & & & & & & & & $(0,0109)$ & $(0,0109)$ \\
\hline \multirow[t]{2}{*}{ Conta-própria agrícola } & & & & & & & & 0,0062 & 0,0064 \\
\hline & & & & & & & & $(0,0119)$ & $(0,0119)$ \\
\hline \multirow[t]{2}{*}{ Especialista autônomo } & & & & & & & & 1,1126 & 1,1164 \\
\hline & & & & & & & & $(0,0228)$ & $(0,0228)$ \\
\hline \multirow[t]{2}{*}{ Gerente } & & & & & & & & 0,9468 & 0,9508 \\
\hline & & & & & & & & $(0,0144)$ & $(0,0143)$ \\
\hline \multirow[t]{2}{*}{ Especialista } & & & & & & & & 0,9370 & 0,9368 \\
\hline & & & & & & & & $(0,0143)$ & $(0,0143)$ \\
\hline \multirow[t]{2}{*}{ Qualificado } & & & & & & & & 0,4948 & 0,5113 \\
\hline & & & & & & & & $(0,0108)$ & $(0,0108)$ \\
\hline \multirow[t]{2}{*}{ Supervisor } & & & & & & & & 0,5517 & 0,5415 \\
\hline & & & & & & & & $(0,0166)$ & $(0,0166)$ \\
\hline \multirow[t]{2}{*}{ Trabalhador } & & & & & & & & 0,2571 & 0,2688 \\
\hline & & & & & & & & $(0,0079)$ & $(0,0080)$ \\
\hline
\end{tabular}


Tabela 1-A

Coeficientes Estimados da Vantagem Relativa de Renda, em Favor do Homem, em Relação à Mulher, e Variáveis de Controle, de Acordo com Diferentes Modelos Lineares Generalizados

(continuação)

\begin{tabular}{|c|c|c|c|c|c|c|c|c|c|}
\hline Variáveis & Modelo 1 & Modelo 2 & Modelo 3 & Modelo 4 & Modelo 5 & Modelo 6 & Modelo 7 & Modelo 8 & Modelo 9 \\
\hline Conta-própria precário & & & & & & & & $\begin{array}{c}0,0679 \\
(0,0679)\end{array}$ & $\begin{array}{c}0,0846 \\
(0,0098) \\
\end{array}$ \\
\hline Emprego doméstico & & & & & & & & $\begin{array}{c}0,0381 \\
(0,0123) \\
\end{array}$ & $\begin{array}{c}0,1063 \\
(0,0127) \\
\end{array}$ \\
\hline Composição de gênero das ocupações & & & & & & & & & $\begin{array}{l}-0,2157 \\
(0,0097)\end{array}$ \\
\hline
\end{tabular}

Fonte (dados originais): IBGE, 2006.

Nota: Coeficientes estimados com erros padrões (entre parênteses). Estatística Z. 
Tabela 2-A

Coeficientes Estimados da Vantagem Relativa de Renda, em Favor do Homem, em Relação à Mulher, para as Categorias de Classe, sem e com o Controle da Composição Ocupacional de Gênero, através de Modelo Linear Generalizado

\begin{tabular}{|c|c|c|}
\hline Categorias de Classe & $\begin{array}{l}\text { Sem Controle da Composi- } \\
\text { ção Ocupacional de Gênero }\end{array}$ & $\begin{array}{l}\text { Com Controle da Composi- } \\
\text { ção Ocupacional de Gênero }\end{array}$ \\
\hline Capitalista & $\begin{array}{c}0,3800 \\
(0,0601)\end{array}$ & $\begin{array}{r}0,3852 \\
(0,0600)\end{array}$ \\
\hline Pequeno empregador & $\begin{array}{c}0,1814 \\
(0,0228)\end{array}$ & $\begin{array}{c}0,1751 \\
(0,0227)\end{array}$ \\
\hline $\begin{array}{l}\text { Conta-própria } \\
\text { não-agrícola }\end{array}$ & $\begin{array}{c}0,3264 \\
(0,0164)\end{array}$ & $\begin{array}{c}0,2736 \\
(0,0165)\end{array}$ \\
\hline Conta-própria agrícola & $\begin{array}{c}0,4600 \\
(0,0264)\end{array}$ & $\begin{array}{c}0,4617 \\
(0,0264)\end{array}$ \\
\hline $\begin{array}{l}\text { Especialista auto- } \\
\text { empregado }\end{array}$ & $\begin{array}{c}0,2371 \\
(0,0399)\end{array}$ & $\begin{array}{c}0,2125 \\
(0,0398)\end{array}$ \\
\hline Gerente & $\begin{array}{c}0,3466 \\
(0,0240)\end{array}$ & $\begin{array}{c}0,3438 \\
(0,0240)\end{array}$ \\
\hline Empregado especialista & $\begin{array}{c}0,3350 \\
(0,0202)\end{array}$ & $\begin{array}{c}0,2963 \\
(0,0203)\end{array}$ \\
\hline Empregado qualificado & $\begin{array}{c}0,4148 \\
(0,0148)\end{array}$ & $\begin{array}{c}0,3364 \\
(0,0152)\end{array}$ \\
\hline Supervisor & $\begin{array}{c}0,2042 \\
(0,0371)\end{array}$ & $\begin{array}{c}0,1677 \\
(0,0370)\end{array}$ \\
\hline Trabalhador típico & $\begin{array}{c}0,2801 \\
(0,0071)\end{array}$ & $\begin{array}{c}0,2040 \\
(0,0079)\end{array}$ \\
\hline Trabalhador elementar & $\begin{array}{c}0,1693 \\
(0,0149)\end{array}$ & $\begin{array}{c}0,1355 \\
(0,0150)\end{array}$ \\
\hline Conta-própria precário & $\begin{array}{c}0,3688 \\
(0,0121)\end{array}$ & $\begin{array}{c}0,2763 \\
(0,0128)\end{array}$ \\
\hline Empregado doméstico & $\begin{array}{c}0,2460 \\
(0,0256)\end{array}$ & $\begin{array}{c}0,2099 \\
(0,0257)\end{array}$ \\
\hline Geral & $\begin{array}{r}0,3012 \\
(0,0047)\end{array}$ & $\begin{array}{c}0,2410 \\
(0,0054)\end{array}$ \\
\hline
\end{tabular}

Fonte (dados originais): IBGE, 2006.

Nota: Coeficientes estimados com erros padrões (entre parênteses). Estatística Z.

Forma de estimação explicada no item "Tratamento dos efeitos interativos", p. 366. 
Tabela 3-A

Coeficientes Estimados da Vantagem Relativa de Renda de Classe, entre a Categoria Designada e a Categoria de Referência (omitida) de Trabalhador Elementar, entre Homens e Mulheres, através de Modelo Linear Generalizado

\begin{tabular}{|c|c|c|}
\hline Categorias de Classe & Homens & Mulheres \\
\hline Capitalista & $\begin{array}{c}1,9232 \\
(0,0307)\end{array}$ & $\begin{array}{c}1,7126 \\
(0,0544)\end{array}$ \\
\hline Pequeno empregador & $\begin{array}{c}1,1531 \\
(0,0142)\end{array}$ & $\begin{array}{c}1,1410 \\
(0,0240)\end{array}$ \\
\hline Conta-própria não-agrícola & $\begin{array}{c}0,5643 \\
(0,0124)\end{array}$ & $\begin{array}{c}0,4073 \\
(0,0195)\end{array}$ \\
\hline Conta-própria agrícola & $\begin{array}{c}0,0395 \\
(0,0124)\end{array}$ & $\begin{array}{l}-0,2510 \\
(0,0293)\end{array}$ \\
\hline Especialista autônomo & $\begin{array}{c}1,1216 \\
(0,0282)\end{array}$ & $\begin{array}{c}1,0539 \\
(0,0347)\end{array}$ \\
\hline Gerente & $\begin{array}{c}0,9995 \\
(0,0174)\end{array}$ & $\begin{array}{c}0,8222 \\
(0,0235)\end{array}$ \\
\hline Especialista & $\begin{array}{c}0,9892 \\
(0,0183)\end{array}$ & $\begin{array}{c}0,8235 \\
(0,0204)\end{array}$ \\
\hline Qualificado & $\begin{array}{c}0,5919 \\
(0,0138)\end{array}$ & $\begin{array}{c}0,3465 \\
(0,0168)\end{array}$ \\
\hline Supervisor & $\begin{array}{c}0,5673 \\
(0,0185)\end{array}$ & $\begin{array}{c}0,5324 \\
(0,0357)\end{array}$ \\
\hline Trabalhador típico & $\begin{array}{c}0,2852 \\
(0,0090)\end{array}$ & $\begin{array}{c}0,1744 \\
(0,0145)\end{array}$ \\
\hline Conta-própria precário & $\begin{array}{c}0,1309 \\
(0,0115) \\
\end{array}$ & $\begin{array}{l}-0,0684 \\
(0,0165)\end{array}$ \\
\hline Emprego doméstico & $\begin{array}{l}0,0218^{*} \\
(0,0270)\end{array}$ & $\begin{array}{l}-0,0547 \\
(0,0166)\end{array}$ \\
\hline
\end{tabular}

Fonte (dados originais): IBGE, 2006.

Forma de estimação explicada no item "Tratamento dos efeitos interativos", p. 366. Nota: Coeficientes estimados com erros padrões (entre parênteses). Estatística Z.

* Coeficiente estatisticamente não-significativo mesmo no nível de $10 \%$. 


\section{ABSTRACT}

Social Class and Gender Inequality in Brazil

This article investigates the hypothesis that gender inequality in income in Brazil is influenced by the social class context. Class order and occupational segregation act as relevant factors in gender inequality. The effect of social class on the gender wage gap, although less pronounced as compared to interactions between class and race, plays an important "moderating" role on gender disparity, particularly by accentuating the gap in the case of capitalists, managers, and holders of professional qualifications (as assets) and attenuating them in the case of ordinary workers. The study identifies sharp inequality in gender treatment that appears to supersede the inequality in access to valuable contexts and resources, representing a direct effect of gender.

Key words: gender inequality; social class; interactions between class and gender; gender wage gap; Generalized Linear Model

\section{RÉSUMÉ}

\section{Classe Sociale et Inégalité des Sexes au Brésil}

Dans cet article, on cherche à savoir si l'inégalité de revenu selon le sexe au Brésil serait liée à l'appartenance à une classe sociale donnée. L'ordre de classe et la ségrégation professionnelle agissent comme d'importants facteurs médiateurs de l'inégalité selon le sexe. L'effet de la classe sociale sur les écarts selon le sexe, bien que moins aigu lorsqu'on le compare aux interactions entre classe et race, joue un rôle "modérateur" important sur l'inégalité de revenu selon le sexe, en particulier chez les détenteurs de capital, les cadres et ceux qui diposent d'actifs de qualification, dans le sens de leur approfondissement, et les travailleurs primaires, dans le sens de leur allègement. Dans cette étude, on constate une forte inégalité de traitement selon le sexe, qui semble prédominer sur les inégalités d'accès à de considérables contextes et ressources, ce qui représente un effet direct de l'appartenance à l'un des sexes.

Mots-clé: inégalités des sexes; classe sociale; interactions classe et sexe; écarts de revenu liés aux sexe; Modèle Linéaire Généralisé 